\title{
Effects of strong cathodic polarization of the Ni-YSZ interface
}

Hansen, Karin Vels; Chen, Ming; Jacobsen, Torben; Thydén, Karl Tor Sune; Simonsen, Søren Bredmose; Koch, Søren; Mogensen, Mogens Bjerg

\section{Published in:}

Electrochemical Society. Journal

Link to article, DOI:

10.1149/2.0871610jes

Publication date:

2016

Document Version

Peer reviewed version

Link back to DTU Orbit

Citation (APA):

Hansen, K. V., Chen, M., Jacobsen, T., Thydén, K. T. S., Simonsen, S. B., Koch, S., \& Mogensen, M. B. (2016). Effects of strong cathodic polarization of the Ni-YSZ interface. Electrochemical Society. Journal, 163(10), 12171227. https://doi.org/10.1149/2.0871610jes

\section{General rights}

Copyright and moral rights for the publications made accessible in the public portal are retained by the authors and/or other copyright owners and it is a condition of accessing publications that users recognise and abide by the legal requirements associated with these rights.

- Users may download and print one copy of any publication from the public portal for the purpose of private study or research.

- You may not further distribute the material or use it for any profit-making activity or commercial gain

- You may freely distribute the URL identifying the publication in the public portal 


\title{
Effects of strong cathodic polarization of the Ni-YSZ interface
}

Karin Vels Hansen ${ }^{\mathrm{a},}$, Ming Chen ${ }^{\mathrm{a}}$, Torben Jacobsen ${ }^{\mathrm{b}}$, Karl Thydén ${ }^{\mathrm{a}}$, Søren Bredmose Simonsen ${ }^{\mathrm{a}}$, Søren Kocha ${ }^{\mathrm{a}}$ Mogens Bjerg Mogensen ${ }^{\mathrm{a}}$

\footnotetext{
a) Department of Energy Conversion and Storage, Technical University of Denmark, DTU Ris $\varnothing$ Campus, Frederiksborgvej 399, DK-4000 Roskilde, Denmark.

b) Department of Chemistry, Technical University of Denmark, Kemitorvet, Building 207, DK2800, Kgs. Lyngby, Denmark.
}

\begin{abstract}
Long-term strong cathodic polarization experiments of down to $-2.4 \mathrm{~V}$ vs. $E^{\mathrm{o}}\left(\mathrm{O}_{2}\right)$ of the Ni-YSZ interface were performed at $900{ }^{\circ} \mathrm{C}$ in $97 \% \mathrm{H}_{2} / 3 \% \mathrm{H}_{2} \mathrm{O}$ on model electrodes. The Ni-YSZ interface underwent extensive changes and a large affected volume with a complex microstructure and phase distribution resulted. Impedance spectroscopy shows initial decrease but later increase in the series resistance and polarization resistance during the $140-160 \mathrm{~h}$ of polarization, and significant inductive behavior. An intermetallic $\mathrm{Ni}-\mathrm{Zr}$ phase that formed during polarization was preserved when the polarization was kept during cooling, and was identified post-mortem by transmission electron microscopy as $\mathrm{Ni}_{7} \mathrm{Zr}_{2} . \mathrm{ZrO}_{2}$ nanoparticles were formed on the Ni-gas surface next to the Ni-YSZ-gas triple phase boundary. Explanations of the observed features are offered based on electron microscopy and impedance spectroscopy.
\end{abstract}

\section{Introduction}


Degradation in solid oxide electrolysis cells (SOEC) due to increasing polarization is a serious issue for the high performance needed for successful implementation of this energy storage technology in the future sustainable energy society. During operation the hydrogen electrode may experience a strong cathodic polarization when operated at high current density. With increasing polarization $\mathrm{ZrO}_{2}$ will be reduced, resulting in formation of a solid solution of $\mathrm{Zr}$ in $\mathrm{Ni}$, formation of intermetallic $\mathrm{Ni}-\mathrm{Zr}$ phases and pure zirconium, and as a result irreversible microstructural changes occur (1-9).

Reduction of zirconia in hydrogen has been studied previously (10-16) and it is found that two steps of reduction occurs. At low temperature zirconia obtains a slightly yellow or grey color due to trapping of electrons by impurities such as Fe. At higher temperatures zirconia darkens or becomes black which is attributed to trapping of electrons in oxygen vacancies $(10,11)$. Electrochemical reduction of zirconia has been studied by several authors (12-14) and the blackening has been observed in zirconia single crystals of varying composition as tongue-shaped areas moving through the crystal from the cathode towards the anode. The blackening depends on the applied potential, temperature and time, and progresses slower in polycrystalline materials than in single crystals (12). It was observed that the blackened zirconia was fragile and above a current density of $5 \mathrm{~A} / \mathrm{cm}^{2}$ the zirconia single crystals would crack (14), however, no change in lattice parameter, density or elastic constants was accompanying the blackening $(14,15)$. The blackened zirconia exhibits a high electronic conductivity as well as ionic conductivity $(12,13)$ and the interface between blackened zirconia and white zirconia acts as a virtual cathode (12).

Wagner et al. (3) studied electrochemically induced changes at the Ni-YSZ interface in vacuum at $10^{-3} \mathrm{~Pa}$ and $927^{\circ} \mathrm{C}$. Two types of experiments were carried out; either the polarization was kept all through the experiment including during cooling, or the polarization was released and the cooling carried out at open circuit voltage (OCV). In the first case they observed a decomposition of 
zirconia at strong cathodic overpotentials and formation of the intermetallic compound $\mathrm{Ni}_{5} \mathrm{Zr}$ at the Ni-YSZ interface and, dispersed in this, nanosized yttria-rich particles. Ending the polarization caused reoxidation of the main part of the $\mathrm{Ni}_{5} \mathrm{Zr}$, forming $\mathrm{Ni}$ and monoclinic $\mathrm{ZrO}_{2}$ in a columnar pattern. Between this and the $\mathrm{Ni}$ a thin layer of $\mathrm{Ni}_{5} \mathrm{Zr}$ was found.

Klotz et al. have used very short-term reverse current treatment to demonstrate a decrease of the polarization resistance on solid oxide cells $(4,17)$ and in a Ni-YSZ model electrode system (5). The treatment caused a distinct change in the Ni-YSZ interface with development of a nanostructured layer with $\mathrm{Ni}$ and zirconia networks and nanoporosity, contributing to a larger triple phase boundary (TPB) that was suggested to explain the improved performance.

Graves (18) investigated strong cathodic polarization on model Ni electrodes on YSZ with a bent and electropolished Ni wire on a polished YSZ electrolyte. The contact area showed a nanostructured Ni-YSZ composite.

Høgh (19) applied strong cathodic polarization to Ni point electrodes on stabilized zirconia single crystals in a setup similar to the one reported by us. He observed an immediate and considerable decrease in the polarization resistance. The polarization was not as strong as in the present paper but strong enough to reduce impurity oxides accumulated at the TPB, e.g. $\mathrm{SiO}_{2}$, which was considered the reason for the changed electrochemical properties as the reduction of the impurities can unblock the triple phase boundary.

Previous long-term experiments have shown formation of nanoparticles of $\mathrm{ZrO}_{2}$ on the $\mathrm{Ni}$ grains in cells tested at high current densities, i.e. strong cathodic polarization of the steam-hydrogen|Ni-YSZ electrode $(1,9)$. The suggested mechanism is reduction of $\mathrm{ZrO}_{2}$ at the Ni-YSZ interface, dissolution and migration of $\mathrm{Zr}$ in $\mathrm{Ni}$, and precipitation of $\mathrm{ZrO}_{2}$, where the oxygen activity is higher, e.g. at $\mathrm{Ni}$ surfaces or Ni-Ni grain boundaries. Thermodynamic calculations show that this process is realistic at these test conditions (1). However, the mechanism in (1) does not explain why the $\mathrm{ZrO}_{2}$ 
precipitates and stays as nanoparticles over hundreds of hours at temperatures in the range of $800-$ $900{ }^{\circ} \mathrm{C}$, and it cannot explain the high concentration of $\mathrm{ZrO}_{2}$ nanoparticles observed at the Ni-YSZ interface.

The experiments reported in the present paper were carried out in order to further elucidate in detail the effects on the microstructural changes of the Ni-YSZ interface caused by strong cathodic polarization and possibly find the cause for the formation of nanoparticles.

\section{Experimental}

Ni wires (99.999\% purity, Johnson Matthey, $0.5 \mathrm{~mm}$ in diameter) were bent to a U-shape and heat treated for $72 \mathrm{~h}$ at $1000{ }^{\circ} \mathrm{C}$ in $9 \% \mathrm{H}_{2} / 3 \% \mathrm{H}_{2} \mathrm{O}$ in $\mathrm{N}_{2}$. Subsequently, they were mounted in a double bore alumina tube (Figure 1) and electropolished (19). 8 mol\% yttria-stabilized zirconia (YSZ, TZ8Y, Tosoh) disks were pressed, sintered at $1500{ }^{\circ} \mathrm{C}$ for 2 hours in air and then polished on one side, ending with a $0.1 \mu \mathrm{m}$ diamond suspension. The final diameter and thickness were $1.5 \mathrm{~cm}$ and $2.5 \mathrm{~mm}$. The unpolished sides of the YSZ disks were painted with Pt paste and placed on a Pt mesh for current collection. The YSZ disks were then mounted in a two-electrode set-up where the Ni wires were pressed against the polished YSZ surfaces with a load of $300 \mathrm{~g}$ thus forming a point electrode. The set-up held four samples. All experiments were carried out at $900{ }^{\circ} \mathrm{C}$ in $97 \% \mathrm{H}_{2} / 3 \%$ $\mathrm{H}_{2} \mathrm{O}$. A $p \mathrm{O}_{2}$ sensor was located a few centimeters away from the samples and the oxygen partial pressure was logged continuously.

Electrochemical impedance spectroscopy (EIS) was performed with a 1255 Solartron Frequency Response Analyser and 1287 Electrochemical Interface. All Ni electrodes were left at OCV until the series resistance $\left(R_{S}\right)$ was stable. The electrodes were then cathodically polarized one at a time and EIS was performed during the polarization. After the polarization was released, EIS at OCV was performed. For one electrode (C1p) the electrode potential was kept during cooling. Table 1 lists the Ni-YSZ half cells and conditions. 
The potential of the polarized electrodes relative to a standard oxygen electrode $\left(1 \mathrm{bar}, 900{ }^{\circ} \mathrm{C}\right)$, $E^{o}\left(\mathrm{O}_{2}\right)$, and corrected for the potential drop in the electrolyte was calculated as

$$
E(\mathrm{Ni})=E^{e q}(\mathrm{Ni})-E^{o}\left(\mathrm{O}_{2}\right)+\eta-i R_{S}(1)
$$

Here $E^{e q}(\mathrm{Ni})$ is the equilibrium potential vs. $E^{\mathrm{o}}\left(\mathrm{O}_{2}\right)$ calculated from the oxygen partial pressure determined by the $p \mathrm{O}_{2}$ sensor. The $p \mathrm{O}_{2}$ sensor voltage was in all experiments close to $-1080 \mathrm{mV}$ corresponding to $2.3 \cdot 10^{-19}$ bar. The difference $\eta-i R_{S}$ is the polarization corrected for the ohmic polarization and $R_{S}$ is determined by EIS. Due to variations in $R_{s}$ and $i$ during the polarisation, the electrode potentials in Table 1 should be taken as best estimates, within $100 \mathrm{mV}$. In the following all potentials are relative to $E^{\mathrm{O}}\left(\mathrm{O}_{2}\right)$.

Scanning electron microscopy (SEM, Zeiss Supra-35) of contact areas on both the Ni wires and on the YSZ pellets was performed. Energy dispersive X-ray spectroscopy (EDS) was performed on selected electrodes. Subsequently, the Ni wires and YSZ disks were cast in epoxy, cut and polished, ending with $0.1 \mu \mathrm{m}$ diamond paste, to disclose a cross section of the Ni-YSZ interface and reaction volume. EDS was performed at an acceleration voltage of $10 \mathrm{kV}$, resulting in an interaction depth of less than $500 \mathrm{~nm}$.

Scanning transmission electron microscopy (STEM) imaging in combination with EDS was performed by using a JEM 2100 equipped with a LaB6 source operated at 200kV, a high annular angle dark field (HAADF) STEM detector, and a JEOL JED-2300T EDS detector. The specimen for STEM was prepared by focused ion beam (FIB) milling using a $30 \mathrm{kV}$ Ga ion beam (Zeiss Crossbeam XB1540). From the acquired STEM images, particle sizes were measured by manually outlining the particle perimeters, using the software ImageJ and converting the measured projected particle areas to particle diameters using a circular approximation. Quantifications of the EDS spectra are calculated by using the Cliff-Lorimer equation using k-factors measured from two standards: 1) an 8 YSZ powder dryly dispersed on a C/Cu TEM grid and 2) a $\mathrm{Hf}_{0.6} \mathrm{Zr}_{0.4} \mathrm{NiSb}_{0.98} \mathrm{Sn}_{0.02}$ 
powder dryly dispersed on a C/Au TEM grid. The errors of the EDS quantifications were estimated from the difference between expected and measured values of the standards as function of the sum of the integrated intensities of the relevant peaks. This estimate does not take the heterogeneous structure of the Ni-YSZ FIB'ed lamella into account. Therefore the errors could be higher due to possible overlapping regions with different compositions as well as background signals from neighbour regions.

\section{Results}

All cells have a stable $R_{s}$ during the initial measurements at OCV with values between 150 and 220 $\Omega$. The complex plane plots show one arc with summit frequencies in the range 3-8 Hz and DC polarization resistances, $R_{p}$, in the range $23-100 \mathrm{k} \Omega$. For polarizations resulting in electrode potentials less negative than $-2.1 \mathrm{~V} R_{s}$ is stable whereas $R_{p}$ changed substantially during polarization, both increasing as well as decreasing values were obtained. Polarizing the electrodes further to electrode potentials of or below $-2.1 \mathrm{~V}$ resulted in the general trend illustrated in Figure 2 The spectrum obtained at OCV just before polarization shown in Figure 2a appears as a somewhat suppressed arc with a summit frequency of $2.6 \mathrm{~Hz}$. Just after polarization to $-2.2 \mathrm{~V}$ the impedance diagram changed from a single arc into what looks as part of a slightly deformed full circle as seen in Figure $2 \mathrm{~b}, R_{s}$ decreased from the OCV value of $215 \Omega$ to ca. $110 \Omega$, and $R_{p}$ from $100 \mathrm{k} \Omega$ to a few ohm. With time $R_{s}$ as well as the size of the inductive loop decreased yielding the spectrum shown in Figure 2c. Also, it is noted that the summit frequency of the capacitive loop is doubled whereas that of the inductive loop is halved. In the next time span (49-153 h, Figure $2 d)$ the changes in characteristic frequencies are further pronounced and the capacitive arc separates into two arcs, a very depressed high frequency arc covering a still higher frequency range and a low frequency arc coupled to the inductive loop at frequencies two orders of magnitude lower. To obtain $R_{S}$ and to 
check that the data are Kramers-Kronig compliant, i.e. not severely influenced by drift, the equivalent circuit in Figure 3c was fitted to the experimental data. As seen from Figure 2a-d good agreement is obtained between the experimental and the fitted data.

The corresponding $R_{s}$ obtained from fitting is depicted vs. time in Figure $3 \mathrm{a}$ and shows an interesting behavior. First it decreases through a minimum to a local peak followed by a new minimum and peaking. Finally, after $70 \mathrm{~h}$, a slower steady increase is seen. $R_{p}$ (Figure $3 \mathrm{~b}$ ), calculated from the resistance values of the equivalent circuit, shows a somewhat noisy increase with local peaks simultaneously with those of $R_{s}$. The picture of an initial drastic decrease in $R_{S}$ followed by a slower increase was common to all experiments, whereas the pronounced local peaks were only observed for the B1 electrode.

During dismounting, the Ni electrodes that were subjected to the strongest polarizations adhered strongly to the YSZ disks, and parts of the YSZ were attached to the Ni electrodes, forming fracture surface on both the Ni wires and the YSZ disks (Figure 4).

The contact areas were elliptical (Figure 4a, Figure 5a) with axes in the order of 100-150 $\mu \mathrm{m}$ and $350-400 \mu \mathrm{m}$. Those resulting from polarizations from $-2.0 \mathrm{~V}$ vs. $\mathrm{E}^{\circ}\left(\mathrm{O}_{2}\right)$ and stronger were easily distinguished on the YSZ pellets as they were black. For non-polarized electrodes there was only a very weak imprint in the YSZ which probably results from the high pressure, 15-18 MPa, caused by the load. No sign of changes other than flattening of the Ni was observed for these electrodes. The electrode C2 (-2.1 V) showed minor changes to the Ni and YSZ interface, and the electrodes A1, B0, B1 and C1p (-2.2 V to $-2.4 \mathrm{~V})$ showed significant morphological changes to a nanoporous microstructure containing both $\mathrm{Ni}, \mathrm{Y}$ and $\mathrm{Zr}$ in the contact area (Figure $5 \mathrm{~b}$ ). The cross sections of the Ni and the YSZ part of the interfaces of the electrodes with the strongest polarization all showed very complex microstructures and phase distributions. The sketch in Figure 4 shows an overview of the areas. Due to the preparation challenge of polishing enough to expose 
the cross section, it cannot be guaranteed that the analyzed cross sections exactly represent the center of contact (Figure 4a). This is presumably the reason for the observed different thicknesses of the affected regions, which for B1 is $\sim 220 \mu \mathrm{m}$ and for $\mathrm{C} 1 \mathrm{p}$ it is $\sim 100 \mu \mathrm{m}$.

\section{Cross sections}

SEM-EDS was used to determine the composition of the present phases while STEM-EDS, which has a much better resolution, was carried out in a small area around the bright rim (Figure 6a,b). Three distinct phases were found in $\mathrm{C} 1 \mathrm{p}$ : metallic $\mathrm{Ni}$, an intermetallic $\mathrm{Ni}-\mathrm{Zr}$ phase and $\mathrm{ZrO}_{2}$. SEMEDS always resulted in a $\mathrm{Ni} / \mathrm{Zr}$ ratio of 2.8-3.2 of the intermetallics ( $\mathrm{Ni}$ and YSZ part). These measurements will probably overestimate the $\mathrm{Zr}$ content since the probed volume always contains background signal from adjacent phases. STEM-EDS indicated the composition $\mathrm{Ni}_{7} \mathrm{Zr}_{2}$ but as this is only in a very small region, and because a number of intermetallic compositions exist (20), we will in general use the terms "Ni-Zr" or "intermetallic phase".

Figure 6a shows an SEM image of a cross section of the Ni electrode for C1p. The even grey contrast in top part of the $\mathrm{Ni}$ indicates that this region is unaffected by the experiment. Contrary to this, an elongated zone in the center of the image shows variation in both contrast and structure indicating the interaction zone of the Ni with YSZ. The affected area of the Ni electrode can be divided into a central area and the areas on each side of this (indicated with dashed black lines in the figure), close to the contact area border to the YSZ (the original triple phase boundary, TPB). In the central part three distinct phases were found, $\mathrm{Ni}, \mathrm{ZrO}_{2}$ (darkest) and $\mathrm{Ni}-\mathrm{Zr}$ (brightest) while only two phases can be distinguished closer to the TPB (Ni and $\mathrm{ZrO}_{2}$ ).

$\mathrm{Ni}-\mathrm{Zr}$ is found close to the unaffected $\mathrm{Ni}$ and in the bottom of the central part. Figure $5 \mathrm{~b}$ and $\mathrm{c}$ show close ups of the top and bottom part marked in Figure 5a as A and B. The bottom part of the cross section corresponds to the top of the cross section of the YSZ (Figure 8). 
In Figure $6 \mathrm{a}, \mathrm{a} \sim 1 \mu \mathrm{m}$ wide bright rim is observed directly at the border to the unaffected Ni. SEMEDS shows that this is a Ni-Zr intermetallic phase. According to STEM-EDS the mean Ni/Zr ratio in this region is $3.4 \pm 0.1$ ( 8 regions analyzed). This suggests that the intermetallic phase is $\mathrm{Ni}_{7} \mathrm{Zr}_{2}$. In Figure $6 b$ and at higher resolution in Figure $7 a$, it is seen that particles with a size of $1-2 \mu \mathrm{m}$ are located partly in this rim zone and partly in the Ni. SEM-EDS reveals that they consist of $\mathrm{ZrO}_{2}$ and STEM-EDS confirms that they do not contain Y or Ni. According to the STEM-EDS map presented in Figure 7b, a row of Y-rich nanoparticles is located in the Ni-Zr phase below the $\mathrm{ZrO}_{2}$ particles. Below the bright contrast intermetallic zone there is a two-phase microstructure comprising $\mathrm{Ni}$ and $\mathrm{ZrO}_{2}$ (Figure 6b) as determined by SEM-EDS. $\mathrm{ZrO}_{2}$ is distributed as islands in the connected Ni phase. This structure is termed the intermixed $\mathrm{Ni}-\mathrm{ZrO}_{2}$ structure. Nanoparticles $(<100 \mathrm{~nm}$ in diameter) are present in both $\mathrm{Ni}$ and $\mathrm{ZrO}_{2}$, (Figure $6 \mathrm{~b}$ and Figure 7). STEM-EDS reveals that these are Y-rich and O-containing particles (Figure 7c-d).

The zone with the intermixed microstructure has a thickness of $\sim 30 \mu \mathrm{m}$, after which the $\mathrm{Ni}-\mathrm{Zr}$ phase appears again (Figure 6a), first as spots in the intermixed structure, and below this it transforms into the microstructure shown in Figure $6 \mathrm{c}$ where the $\mathrm{Ni}-\mathrm{Zr}$ phase is dominating with patches of $\mathrm{ZrO}_{2}$ and large porous areas. Metallic Ni is not present in this region.

Closer to the TPB (Figure 6a, in the regions outside the dashed lines) the intermixed structure of Ni and $\mathrm{ZrO}_{2}$ is finer than in the central part. Pores are present and cracks leading to the TPB are seen in both sides.

The YSZ part of the cross section of C1p is shown in Figure 8. The thickness of the affected zone is $\sim 40 \mu \mathrm{m}$. In the top the microstructure is, as expected, similar to the lower center part of the cross section of the Ni part (Figure 6c), with the Ni-Zr phase, $\mathrm{ZrO}_{2}$ and large porosities. Both $\mathrm{Ni}-\mathrm{Zr}$ and $\mathrm{ZrO}_{2}$ contain nanoparticles ( $<100 \mathrm{~nm}$ in diameter) (Figure 9). These presumably contain $\mathrm{Y}$, as $\mathrm{Y}$ is also found with EDS. 
Below this, a very dense zone (Figure 8b, c), consisting of $\mathrm{ZrO}_{2}$ and $\mathrm{Y}$-rich nanoparticles is found. Below the dense zone a 7-8 $\mu \mathrm{m}$ thick $\mathrm{Ni}-\mathrm{Zr}$ zone is located, in which inclusions of an Y-rich oxide is found (Figure 8c). Ni-Zr is found in YSZ grain boundaries and triple points (Figure 8c, Figure 10) to a depth of at least $20 \mu \mathrm{m}$ below the Ni-Zr zone. Figure 11 presents a schematic of the entire reaction volume for $\mathrm{C} 1 \mathrm{p}$.

Figure 12 shows a part of the Ni-YSZ cross section of A2 after a three minutes long polarization at $2.0 \mathrm{~V}$. A $5 \mu \mathrm{m}$ wide zone with thin Ni layers (bright) and $\mathrm{ZrO}_{2}$ layers (dark) has formed. Some layers include nanoporosity which is also found at the edge of the layered zone next to the $\mathrm{Ni}$ and YSZ, respectively.

Figure 13 shows the $\mathrm{Ni}$ part of the cross section of $\mathrm{B} 1$, for which the potential of $-2.2 \mathrm{~V}$ was released before cooling. In the reaction volume two distinct regions are found. Closest to the $\mathrm{Ni}$ (Figure 13b) there is the intermixed $\mathrm{Ni}$ and $\mathrm{ZrO}_{2}$ microstructure. $\mathrm{Y}$ is also present, presumably in nanoparticles similar to $\mathrm{C} 1 \mathrm{p}$. This structure is quite similar to the corresponding region for $\mathrm{C} 1 \mathrm{p}$ (Figure 6) except that there is no intermetallic phase present.

Figure $13 \mathrm{c}$ shows a magnified image of the lower part of the interaction region which is porous and has a very inhomogeneous structure. It consists mainly of zirconia (grey), porosities (dark) and nanosized Ni particles (lightest grey) and there is a hint of a layered structure with dense and porous areas and thin Ni layers. Yttrium is also detected but the distribution seems to be very inhomogeneous as some points show an $\mathrm{Y} / \mathrm{Zr}$ ratio around 0.1 and in others a ratio of 0.24 was detected. The yttrium is therefore likely present as yttria nanoparticles as also observed for electrode C1p (Figure 7, Figure 9).

In the YSZ part of the cross section (Figure 14) the inhomogeneous microstructure continues and varies from the microstructures seen in Figure 14b with lenticular features, through a region with a less distinct microstructure and to the region seen in Figure 14c, where linear features extending 
radially from the interface, i.e. following the current lines, are observed. The linear features consist partly of nanoporosity. Compared to the microstructure of the original YSZ grains, the microstructure with dense $\mathrm{ZrO}_{2}$ and large pores/open lines perpendicular to the current field does not seem to be related original grain boundaries. This structure is found along the outer edge of the affected region. Between this region and the apparently unaffected YSZ below, a nanoporous mixture of Ni and yttria/zirconia is separating the YSZ grains. EDS measurements of the YSZ cross section show finely distributed nanosized Ni particles in the whole region. The measured Ni content ranges from 10-11 at $\%$ in the area shown in Figure $14 \mathrm{~b}$ to 3-4 at\% Ni in the area shown in Figure 14c. Ni is detected even if it is not visible as particles. EDS of the grain boundaries between the YSZ grains seen in the lower left corner in Figure 14c shows 89 at\% Ni. The Y/Zr ratio varies between $\sim 0.18$ found in the YSZ below the affected area to $0.22-$ 0.26 in the Ni-containing grain boundaries, the area with linear features and the boundaries around the lenticular grains in the top of the cross section.

\section{Nanoparticles on Ni electrodes}

In addition to the microscopy analysis of the sample cross sections, the surface of the Ni electrode was analyzed. Here, nanoparticles were found on the Ni electrodes subjected to the strongest polarisation. They were located from immediately outside the contact area and a distance of more than $100 \mu \mathrm{m}$ away from it. The concentration of the particles is higher closer to the contact area as seen in Figure 15 where the contact area is indicated by a white arrow. The nanoparticles were up to $200 \mathrm{~nm}$ in size and showed different shapes, from rods to donuts and flowers. Larger dendritic particles were also found immediately outside the contact area, especially on electrodes subjected to less strong polarization. EDS measurements indicate that many of the particles close to the contact area contains $\mathrm{Zr}$ and $\mathrm{O}$. Some particles further away from the contact contained $\mathrm{Mg}, \mathrm{Si}$ and $\mathrm{Al}$. 


\section{Discussion}

\section{Interface microstructure}

The strong adhesion between the Ni electrode and the YSZ caused parts of the YSZ to be torn out when lifting up the Ni wire on strongly polarised electrodes. The fracture in the YSZ pellet occurs in the weakest zone, which is clearly somewhere in the porous zone below the original Ni-YSZ interface (Figure 6, Figure 11). Parts of the YSZ polished surface next to the contact area adhered to the Ni wire when they were taken apart, thus pointing to the location of the original Ni-YSZ interface in the cross section (Figure 5a). The fracture surfaces show a porous microstructure with nanosized particles, which is similar to what was observed previously $(4,5)$. The contact areas on the electrodes with the strongest polarization appeared black. Blackening of zirconia is a wellknown phenomenon caused by color centers consisting of free electrons trapped in oxygen vacancies which are formed during strong cathodic polarization of YSZ causing electron injection into YSZ $(12,21)$. Blackening of zirconia leads to changed properties as reported by $(12,13,19)$, such as increased electrical conductivity and decreased polarization resistance of Ni-YSZ model electrodes. A significant decrease in the electrolyte and polarization resistance upon reduction was observed for all electrodes in the present study.

\section{Cross-sectional microstructures}

The boundary between the porous zone and the $\mathrm{Ni}-\mathrm{ZrO}_{2}$ intermixed zone (Figure 6, Figure 13) approximately corresponds to the original Ni-YSZ interface. All electrodes except C1p were oxidized when the polarization was released, i.e. there is only $\mathrm{Ni}$ and $\mathrm{ZrO}_{2}$ present and no intermetallic phase has survived. Contrary to this, in $\mathrm{C} 1 \mathrm{p}$ which was polarised during cooling an intermetallic Ni-Zr phase was present after cooling (Figure 6, Figure 7). It should be noted that in this case a partial oxidation may have occurred during cooling when the DC resistance had grown 
too high to prevent such an oxidation by water. The presence of the intermetallic phase makes this electrode particularly interesting and it is discussed in detail below.

The thickness of the interaction volumes depends on the length of the period, i.e. A2 (3 min) has a 4-5 $\mu \mathrm{m}$ thick zone of an intermixed $\mathrm{Ni}-\mathrm{ZrO}_{2}$ structure whereas the $140 \mathrm{~h}$ of polarization produced a 100-200 $\mu \mathrm{m}$ thick inhomogeneous interaction volume. Szász et al. (5) reported a thickness of the newly formed layer consisting of interconnected Ni network with embedded YSZ of $1.1 \mu \mathrm{m}$ for a reverse current treatment time of $10 \mathrm{~s}$ and $0.3 \mu \mathrm{m}$ for $1 \mathrm{~s}$, and Wagner et al. (2) found a $\sim 10 \mu \mathrm{m}$ thick reaction layer after 130 min of polarization. This shows that initially the reduction proceeds quite quickly but at some point it slows considerably It seems that the above data are not contradicting a diffusion controlled process following a square-root-of-time law as we expect based on our observations reported below. The complex microstructure present in e.g. C1p cannot be explained simply by a steady reduction process; other events must have influenced the development of the affected volume.

\section{Reaction volumes of electrode C1p polarized during cool down}

The Ni-Zr intermetallic phase in the C1p sample was found $50 \mu \mathrm{m}$ below the original Ni-YSZ interface and also in a zone at the border of the unaffected $\mathrm{Ni}$, but only in the central part, where the conditions must have been sufficiently reducing despite that oxidation occurred in other parts of the affected area. Close to the original Ni-YSZ- $\mathrm{H}_{2} / \mathrm{H}_{2} \mathrm{O}$ TPB there is no Ni-Zr but only the intermixed microstructure of $\mathrm{Ni}$ and $\mathrm{ZrO}_{2}$, which is a result of a re-oxidation of the $\mathrm{Ni}-\mathrm{Zr}$ phase $(3,5)$. This points to a local re-oxidation around the TPB, by reaction of $\mathrm{H}_{2} \mathrm{O}$ with the $\mathrm{Ni}-\mathrm{Zr}$ phase. Further, the intermixed microstructure of electrically connected $\mathrm{Ni}$ and $\mathrm{ZrO}_{2}$ islands was found in a coarse (Figure 6b) and a fine version Figure 6a, near the TPB). The finer structure found close to the original TPB can possibly be explained by faster re-oxidation due to the presence of $\mathrm{H}_{2} \mathrm{O}$. The 
oxidized zone stretched all the way from one edge to the other, disconnecting the $\mathrm{Ni}-\mathrm{Zr}$ phase above and below.

Y-O rich nanoparticles are present in both the $\mathrm{Ni}$ and the $\mathrm{ZrO}_{2}$ in this zone. A similar intermixed microstructure containing Y-rich nanoparticles in the Ni areas was observed by Szász et al. (5) with TEM. Yttria nanoparticles in $\mathrm{Ni}_{5} \mathrm{Zr}$ were found by Wagner et al. $(2,3)$ and consisted of yttria, with less than 20 at $\% \mathrm{Zr}$, and the authors suggest that the particles are formed from yttria left during the reduction of YSZ because the polarization was not sufficient to reduce $\mathrm{Y}_{2} \mathrm{O}_{3}$. The yttria eventually formed an ultra-thin layer at the Ni-YSZ interface and may have formed a diffusion barrier for Ni and $\mathrm{Zr}$. The yttria layer broke at a certain thickness up and allowed diffusion through it and thus the formation of $\mathrm{Ni}_{5} \mathrm{Zr}$ in pockets in the electrolyte surface, leaving yttria islands in the $\mathrm{Ni}_{5} \mathrm{Zr}(3)$. Yttria has a reduction potential of $-2.7 \mathrm{~V}\left(\right.$ or $\mathrm{pO}_{2}=3 \cdot 10^{-47}$ bar) and the electrode potential of $\mathrm{C} 1 \mathrm{p}$ was thus not sufficient to reduce yttria. It is remarkable that yttria is found close to the unchanged $\mathrm{Ni}$, i.e. far from the original Ni-YSZ interface. Yttrium is reported to be effectively insoluble in Ni at the present conditions (22).

The high density of yttria nanoparticles at the Ni-intermetallic boundary (Figure $7 \mathrm{~b}$ ) may be due to the difference in the diffusion rates of $\mathrm{Ni}$ in the intermetallic phase and that of $\mathrm{Zr}$ in $\mathrm{Ni}$. The diffusion rate of $\mathrm{Ni}$ is 10 times larger than that of $\mathrm{Zr}$ in $\mathrm{Ni}_{7} \mathrm{Zr}_{2}(20)$, and therefore the boundary between the intermetallic and the Ni phase will move from its original position into the Ni phase. As the immobile yttria particles are left behind when $\mathrm{Zr}$ diffuses into the Ni phase, they accumulate at the interface serving as Kirkendall markers.

It is noted that the zirconia in the reaction volume always contains yttria nanoparticles. Thus, it is not original YSZ that has been encapsulated in the intermetallic phase, but the nanoparticles in the YSZ and intermetallic phase present in the YSZ part of the affected volume must be formed during the initial reduction of YSZ as suggested by (3). 
The $\mathrm{ZrO}_{2}$ grains present in the YSZ part of the affected volume is formed by reoxidation of the intermetallic phase as evidenced by the yttria nanoparticles. The $\mathrm{ZrO}_{2}$ grains seem to be encapsulated in the intermetallic Ni-Zr phase (Figure $6 \mathrm{c}$ and Figure $8 \mathrm{~b}$ ). If the zirconia grains were formed by oxidation of $\mathrm{Ni}-\mathrm{Zr}$ at the end of the experiment, they should be surrounded by $\mathrm{Ni}$ with a very low $\mathrm{Zr}$ concentration. This could point towards an oxidation taking place in an earlier stage, after which the excess $\mathrm{Ni}$ is transferred to the electrode-electrolyte interface. If later on an ionic path to the electrolyte becomes available, the zirconia may be partially re-reduced and the grains may be embedded in the intermetallic phase.

Comparing C1p with the results of Wagner et al. (3) we see similarities with both their experiments, i.e. the one where polarization was kept, and the one where the potential was released. In the first case it is the $\sim 7 \mu \mathrm{m}$ thick Ni-Zr layer next to the unchanged YSZ found in C1p, and in the second case it is the rim of $\mathrm{Ni}-\mathrm{Zr}$ next to the unchanged $\mathrm{Ni}$ and the characteristic microstructure with intermixed $\mathrm{Ni}$ and $\mathrm{ZrO}_{2}$ structure, which are present in $\mathrm{C} 1 \mathrm{p}$ even though the polarization was kept during cooling. The $\mathrm{Ni}-\mathrm{ZrO}_{2}$ intermixed structure is thus the result of oxidation, but in a narrow region next to the $\mathrm{Ni}$ the electrode potential could be kept low enough to preserve a little intermetallic phase.

The interconnected $\mathrm{Ni}-\mathrm{Zr}$ in the central part of the reaction volume provides electronic contact from the $\mathrm{Ni}-\mathrm{Zr}$ above and below this re-oxidized zone. Even though there is a dense $\mathrm{ZrO}_{2}$ zone above the $\mathrm{Ni}-\mathrm{Zr}$ zone next to the unaffected YSZ, it seems that there is contact at the edges, and also it must be kept in mind that the images shown are only a view of one cross section through the interaction volume. The presence of $\mathrm{ZrO}_{2}$ in the otherwise reduced zone indicates a previous oxidation event. Yttria nanoparticles found everywhere in the affected zone indicate that all YSZ have been reduced or all $\mathrm{Zr}$ has dissolved and formed intermetallic $\mathrm{Ni}-\mathrm{Zr}$, as yttria is left out from the YSZ during reduction. 
The Ni-Zr particles found in the unaffected YSZ up to $20 \mu \mathrm{m}$ below the Ni-Zr zone must have contact to the Ni-Zr zone in three dimensions. Apparently the mobile Ni can migrate through the $\mathrm{Ni}-\mathrm{Zr}$ phase until it reaches a location where it forms Ni-Zr. YSZ grain boundaries are easy access paths and a slow formation of intermetallic $\mathrm{Ni}-\mathrm{Zr}$ occurs along them, i.e. the potential is low enough to allow $\mathrm{Zr}$ dissolution or reduction far below the $\mathrm{Ni}-\mathrm{Zr}$ zone. $\mathrm{Ni}$ and $\mathrm{ZrO}_{2}$ found along the $\mathrm{YSZ}$ grain boundaries in $\mathrm{B} 1$ result from oxidation of intermetallic phase.

In the hydrogen atmosphere the $p \mathrm{O}_{2}$ monitor shows an oxygen partial pressure of $2.3 \cdot 10^{-19}$ bar. With the polarization of $-1.4 \mathrm{~V}$ applied, the potential of the electrode, relative to a standard electrode with $p \mathrm{O}_{2}=1$ bar and corrected for $i R$ drop, is $-2.4 \mathrm{~V}$ (corresponding to $p \mathrm{O}_{2}=4 \cdot 10^{-42}$ bar). According to Chen et al. (1) zirconia will be reduced to $\mathrm{Zr}$ metal below $1.8 \cdot 10^{-39}$ bar $(-2.25 \mathrm{~V})$ at $900{ }^{\circ} \mathrm{C}$. The Ni$\mathrm{Zr}$ phase diagram shows at $900{ }^{\circ} \mathrm{C}$ a low solubility of $\mathrm{Zr}$ in $\mathrm{Ni}$ (less than a few atom percent) followed by a number of intermetallic compounds: $\mathrm{Ni}_{5} \mathrm{Zr}, \mathrm{Ni}_{7} \mathrm{Zr}_{2}, \mathrm{Ni}_{3} \mathrm{Zr}, \mathrm{Ni}_{21} \mathrm{Zr}_{8}, \mathrm{Ni}_{4} \mathrm{Zr}_{3}, \mathrm{Ni}_{11} \mathrm{Zr}_{9}$, $\mathrm{NiZr}, \mathrm{NiZr}_{2}(1)$ that may be formed at higher oxygen partial pressures. However, the post mortem EDS analysis shows no phases with a $\mathrm{Zr}$ content higher than $\mathrm{Ni}_{7} \mathrm{Zr}_{2}$. In contact with metallic $\mathrm{Ni}$ the intermetallic compound $\mathrm{Ni}_{7} \mathrm{Zr}_{2}$ may be formed at oxygen partial pressures up to $2.45 \cdot 10^{-32}$ bar (23) $(-1.8 \mathrm{~V})$. Thus, at the applied polarization, YSZ will be reduced on the electrode surface and form a layer of $\mathrm{Ni}-\mathrm{Zr}$, e.g. $\mathrm{Ni}_{7} \mathrm{Zr}_{2}$, at the interface:

$$
2 \mathrm{ZrO}_{2}+7 \mathrm{Ni}+8 \mathrm{e}^{-} \rightarrow \mathrm{Ni}_{7} \mathrm{Zr}_{2}+4 \mathrm{O}^{2-}
$$

At the Ni side of this layer $\mathrm{Zr}$ will diffuse into the Ni phase forming a solid solution. For the reduction to proceed $\mathrm{Ni}$ must be supplied from the $\mathrm{Ni}$ phase by diffusion through the $\mathrm{Ni}-\mathrm{Zr}$ layer, and this may very well be the rate determining process. Correspondingly, there is a net diffusion of $\mathrm{Zr}$ from the electrode-electrolyte interface making Ni-Zr grow into Ni (Figure 16a).

During the initial reduction period (first $15 \mathrm{~h}$ ) the series resistance, $R_{s}$, determined from the impedance measurements drops by almost a factor of three as seen from Figure 3a. This is most 
likely caused by an introduction of electronic conductivity in the YSZ and the change of the planar electrode surface into a curved surface (Figure 16b).

As seen from Figure 6 and Figure 8 a porous phase consisting of the intermetallic phase with zirconia islands is found between the active electrode surface and the Ni phase. In the interdiffusion of metals, voids may be formed in the diffusion zone according to the Kirkendall effect (24), and additionally the volume reduction involved in the reduction of zirconia leaves an empty space. Apparently the transport of $\mathrm{Ni}$ is sufficiently fast to avoid pore formation on the outer surface, and consequently pores are formed inside the $\mathrm{Ni}-\mathrm{Zr}$ phase (Figure 16c).

Figure 3 a shows spikes in $R_{s}$ after $35 \mathrm{~h}$ and they are accompanied by a steady increase starting after $70 \mathrm{~h}$, and as seen from Figure $2 \mathrm{c}$ the capacitive impedance arc has grown relative to the inductive arc and shifted toward higher frequencies. Also, $\mathrm{R}_{p}$, as seen in Figure 3b, increases from very low, possibly negative values, to around $150 \Omega$. Since the electrode-electrolyte contact is not likely to change much during the reduction, the most reasonable explanation seems to be that the interior of the $\mathrm{Ni}-\mathrm{Zr}$ phase is being partially oxidized and the electronic conductivity is decreased.

The process could be the following: As sketched in Figure 16d the growth of the Ni-Zr phase in the YSZ moves the TPB away from the original Ni-YSZ-gas contact leaving a Ni-Zr surface exposed to the gas phase behind. This surface does not have any ionic contact to the YSZ and is therefore not protected from oxidation by the polarization. Consequently it will be oxidized by the water vapor. If the zirconia formed is not dense and/or voids formed behind the active reduction zone have combined into pores, water is able to penetrate into the $\mathrm{Ni}-\mathrm{Zr}$ phase and oxidize zirconium to zirconia leaving more or less percolating Ni.

As a result the electronic conduction from the Ni phase to the reaction zone may be a combination electronic and ionic conduction at higher frequencies that can be described by a transmission line circuit with the electronic path dominating at low frequencies. The spikes in $R_{s}$ might reflect 
electronic connections being disrupted in the oxidation process. If later the accompanying volume expansion blocks water supplying pores and there is some ionic connection to the electrolyte, zirconia in the interior of the electrode may be reduced again and electronic pathways reestablished. Also pores may be formed again and the internal oxidation process can start again.

This general picture is further corroborated by the impedance diagram in Figure $2 \mathrm{~d}$ where the high frequency arc has shifted to frequencies more than an order of magnitude higher than those in Figure $2 \mathrm{c}$, and the phase angles have decreased significantly.

As seen from Figure 8 and illustrated in Figure 16d, an intermetallic hemispheric shell with a thickness of around $8 \mu \mathrm{m}$ - separated from the main porous body of zirconia and intermetallic compound by a dense layer of zirconia - has been formed in C1p. The formation of a dense zirconia may indicate a change in the reduction mechanism where $\mathrm{Ni}$ is no longer supplied to the reduction zone through the porous intermetallic pathway. Instead zirconia or water may react on surfaces in electronic contact with the $\mathrm{Ni}$ wire and in ionic contact with the bulk electrolyte. The oxygen ions formed can then migrate through the dense zirconia phase and release electrons to the inner surface of the intermetallic shell according to reaction (3).

$$
\mathrm{Ni}_{7} \mathrm{Zr}_{2}+4 \mathrm{O}^{2-} \rightarrow 2 \mathrm{ZrO}_{2}+7 \mathrm{Ni}+8 \mathrm{e}^{-}
$$

The $\mathrm{Ni}$ and electrons liberated is this reaction can now migrate through the shell and participate in the YSZ reduction at the electrode-electrolyte interface as outlined in (Figure 16e).

It is noted that in contrast to a reduction process where $\mathrm{Ni}$ is supplied from the Ni wire, this mechanism, where the volume reduction due to removal of oxygen ions in the growth zone is compensated for in the oxidation process on the backside of the shell. Thus, there is no net transport of voids into the electrode, and the zirconia on the inner side of the shell stays dense. The final oxidation into the $\mathrm{Ni}-\mathrm{ZrO}_{2}$ intermixed microstructure occurred during cooling where the potential could not be sustained and water could penetrate the affected volume (Figure 16f). 


\section{Fully reoxidized reaction volumes}

For the short term-polarization (Figure 12) where the reduced layer is relatively thin the reoxidation results in the formation of a zone with $\mathrm{Ni}$ and $\mathrm{ZrO}_{2}$ nanostructures and some porosity, which is similar to what is found in the literature $(3,5)$. For the long-term polarization where a much more complicated microstructure developed (Figure 13, Figure 14) the re-oxidation caused significant changes. When the dense $\mathrm{Ni}-\mathrm{Zr}$ is re-oxidized the volume will increase because of oxidation of $\mathrm{Zr}$ to $\mathrm{ZrO}_{2}$. This could be the reason for the cracks observed in the YSZ part of the cross section.

\section{Nanoparticles}

During the experiment $\mathrm{Zr}$ from the solid solution diffuses further into the $\mathrm{Ni}$ phase and reaches the outer surface of the Ni wire. Here the redox conditions are determined solely by the gas phase $p\left(\mathrm{O}_{2}\right)$, independent of the electrode polarization as there is no ionic connection to the electrolyte. Thus, $\mathrm{Zr}$ reaching the $\mathrm{Ni}$-gas interface will be oxidized into $\mathrm{ZrO}_{2}$ nanoparticles (Figure 15). The diffusion of $\mathrm{Zr}$ most likely takes place via the $\mathrm{Ni}$ grain boundaries as the solubility of $\mathrm{Zr}$ in $\mathrm{Ni}$ is very low (25).The relatively small mean particle size indicates that the growth is a slow process. Nanoparticles containing impurity elements were also detected and show that impurities of $\mathrm{Mg}, \mathrm{Al}$ and Si oxides in the YSZ electrolyte have been reduced and the metals followed the diffusion of $\mathrm{Zr}$ through the Ni wire. Both $\mathrm{Al}$ and $\mathrm{Si}$ have a large solubility in metallic Ni. According to thermodynamic calculations using FACTSAGE (23), dissolution of Al and Si from the oxides at the $\mathrm{Ni} / \mathrm{YSZ}$ interface into Ni can take place at $p\left(\mathrm{O}_{2}\right)=10^{-20}-10^{-22}$ bar at $900{ }^{\circ} \mathrm{C} . \mathrm{Mg}$ is not soluble in $\mathrm{Ni}$, but can form two intermetallic compounds $\left(\mathrm{MgNi}_{2}\right.$ and $\left.\mathrm{Mg}_{2} \mathrm{Ni}\right)$. Formation of these at the $\mathrm{MgO}(\mathrm{YSZ}) / \mathrm{Ni}$ interface requires a $p\left(\mathrm{O}_{2}\right)$ below $10^{-38}$ bar at $900{ }^{\circ} \mathrm{C}$. 
The $\mathrm{ZrO}_{2}$ and impurity nanoparticles on the $\mathrm{Ni}$ wire surface exposed to the $\mathrm{H}_{2} \mathrm{O}$ containing atmosphere (Figure 15) confirms the hypothesis previously presented $(1,9)$ for strongly cathodically polarized Ni-YSZ composite electrodes even though the particles seem somewhat larger in the present experiment (1). However, compared to the experiments with porous Ni-YSZ composites, the Ni-YSZ interface behaves very differently except for the fact that nanosized structures form in both cases as a result of oxidation of intermetallic phases. We suggest that the differences in appearance may be caused by the amount of materials present and the pressure. The reaction zone in the present experiment is under a uniaxial pressure all the time, and this allows the YSZ reduction reaction to proceed far, without loss of contact between $\mathrm{Ni}$ (or $\mathrm{Ni}-\mathrm{Zr}$ ) happens, whereas in the composite Ni-YSZ-cermet case the contact between Ni particles and YSZ particles is lost relatively early in the experiments $(26,27)$ and the $\mathrm{Zr}$ dissolved in the Ni is re-oxidized by steam. Finally, the temperature of the ref. (1) experiments was slightly lower and the steam partial pressure (the driving force for oxidation) considerably higher. Both features will - everything else equal - cause smaller particles.

\section{Conclusion}

When Ni electrodes are polarized below $-1.8 \mathrm{~V}$ vs. $E^{9}\left(\mathrm{O}_{2}\right)$, or $p \mathrm{O}_{2}=10^{-32}$ bar, YSZ is reduced and $\mathrm{Ni}-\mathrm{Zr}$ intermetallic phase grows from the interface into the electrolyte and also into the Ni phase. Due to its very low reduction potential the yttria content is not reduced, but left as nanoparticles inside the intermetallic phase formed at the electrolyte side of the original interface. Pores are formed inside the intermetallic phase during reduction allowing a partial reoxidation by $\mathrm{H}_{2} \mathrm{O}$ behind the electrode surface. Contrary to short-term experiments the long polarization times result in complex structures possible caused by reduction-oxidation-re-reduction events. Nanoparticles were formed on the free Ni surface exposed to the steam containing gas. 


\section{Acknowledgment}

This work was financially supported by the Danish transmission service operator (TSO)

Energinet.dk through the projects ForskEL 2013-1-12013 “Solid Oxide Electrolysis for Grid Balancing” and ForskEL 2015-1-12276 "Towards SOEC plants in 2020”.

\section{References}

1. M. Chen, Y.-L. Liu, J. J. Bentzen, W. Zhang, X. Sun, A. Hauch, Y. Tao, J. R. Bowen, and P. V. Hendriksen, J. Electrochem. Soc., 160, F883-F891 (2013).

2. T. Wagner, D. Duscher, and R. Kirchheim, J. Mater. Res., 14, 3340-3345 (1999).

3. T. Wagner, R. Kirchheim, and M. Rühle, Acta Metall. Mater., 40, S85-S93 (1992).

4. D. Klotz, B. Butz, A. Leonide, D. Gerthsen, and E. Ivers-Tiffée, ECS Trans., 28, 141-150 (2010).

5. J. Szász, D. Klotz, H. Störmer, D. Gerthsen, and E. Ivers-Tiffée, ECS Trans., 57, 1469-1478 (2013).

6. C. Graves, S. D. Ebbesen, S. H. Jensen, S. B. Simonsen, and M. B. Mogensen, Nat. Mater., 14, 239-244 (2015).

7. Y. Tao, Ph.D. Thesis, Technical University of Denmark (2013).

8. Y. Tao, S. D. Ebbesen, and M. B. Mogensen, Submitted, (2016).

9. W. Zhang, M. Chen, L. Theil Kuhn, J. R. Bowen, and J. J. Bentzen, ChemElectroChem, 1, $520-523(2014)$

10. R. Ben-Michael and D. S. Tannhauser, Appl. Phys. A, 53, 185-188 (1991).

11. D. Eder and R. Kramer, Phys. Chem. Chem. Phys., 4, 795-801 (2002).

12. R. E. W. Casselton, J. Appl. Electrochem., 4, 25-48 (1974).

13. J. Janek and C. Korte, Solid State Ionics, 116, 181-195 (1999). 
14. D. A. Wright, J. S. Thorp, A. Aypar, and H. P. Buckley, J. Mat. Sci., 8, 876-882 (1973).

15. J. M. Farley, J. S. Thorp, J. S. Ross, and G. A. Saunders, J. Mat. Sci., 7, 475-476 (1972).

16. M. Levy, J. Fouletier, and M. Kleitz, Solid State Sci. Technol., 135, 1584-1589 (1988).

17. D. Klotz, B. Butz, A. Leonide, J. Hayd, D. Gerthsen, and E. Ivers-Tiffée, J. Electrochem. Soc., 158, B587-B595 (2011).

18. C. R. Graves, Ph.D. Thesis, Columbia University, USA (2010).

19. J. Høgh, Ph.D. Thesis, Risø National Laboratory, Denmark (2005).

20. T. Paul and A. Paul, J. Phase Equilib. Diffus., 36, 381-389 (2015).

21. D. Eder and R. Kramer, Phys. Chem. Chem. Phys., 4, 795-801 (2002).

22. M. Mezbahul-Islam and M. Medra, Calphad, 33, 478-486 (2009).

23. C. W. Bale, P. Chartrand, S. A. Degterov, G. Eriksson, K. Hack, R. B. Mahfoud, J. Melançon, A. D. Pelton, and S. Petersen, Calphad, 26, 189-228 (2002).

24. D. Kim, J.-H. Chang, J. Park, and J. J. Pak, J. Mater. Sci. : Mater. Electron., 22, 703-716 (2011)

25. C. H. Konrad, R. Völkl, and U. Glatzel, Oxid. Met., 77, 149-165 (2012).

26. M. B. Mogensen, A. Hauch, X. Sun, M. Chen, Y. Tao, S. D. Ebbesen, and P. V. Hendriksen, in: Proc. $12^{\text {th }}$ European SOFC \& SOE Forum, Lucerne, Switzerland., p. A0902 (2016).

27. A. Hauch, K. Brodersen, M. Chen, and M. B. Mogensen, Solid State Ionics, accepted, (2016).

Figures 


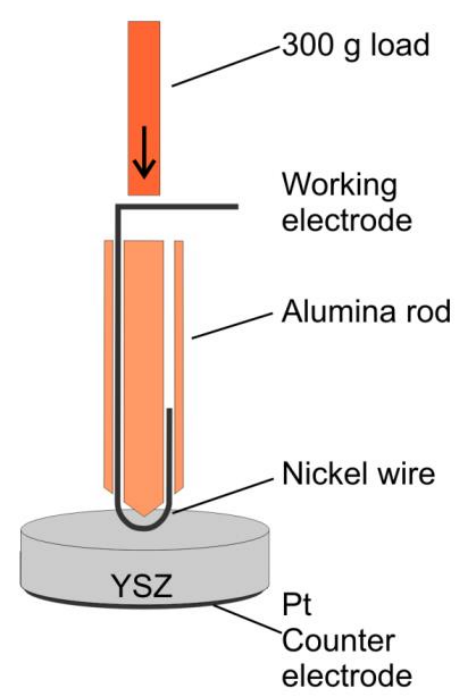

Figure 1.
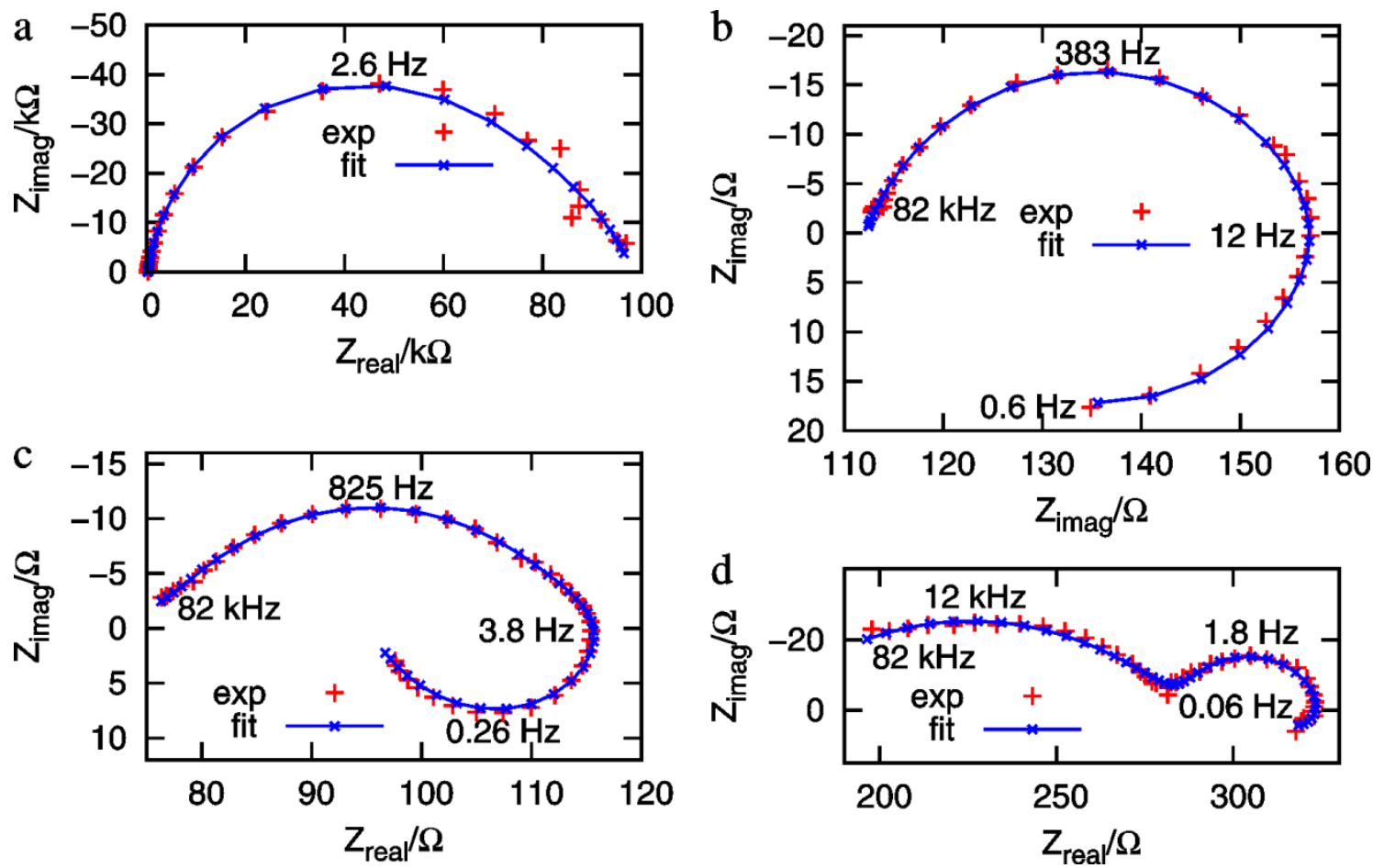

Figure 2 

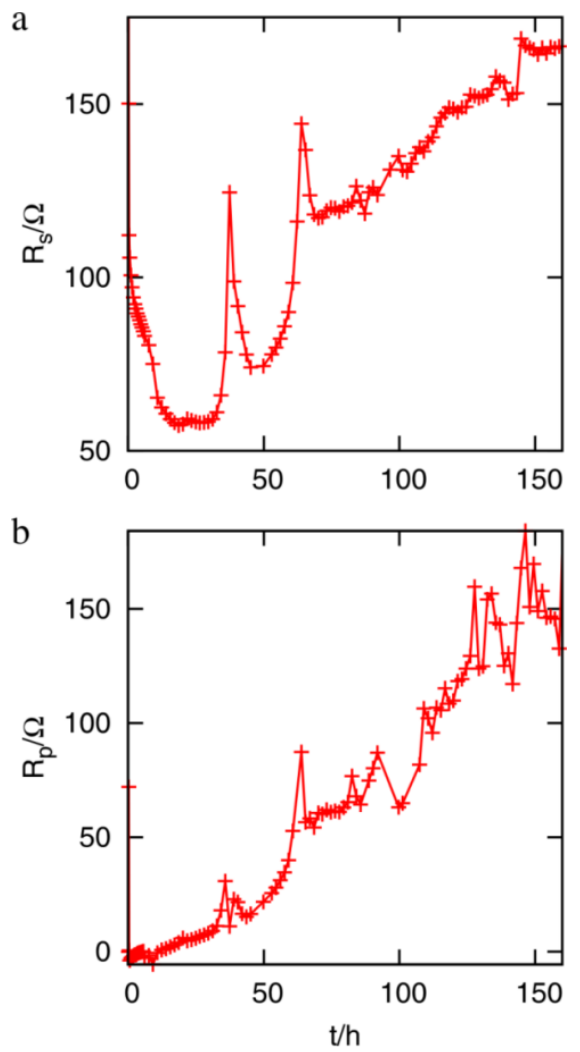

c

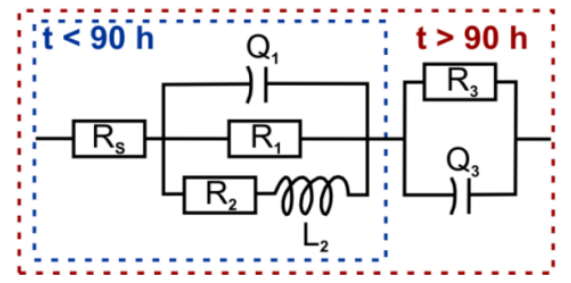

Figure 3.

a

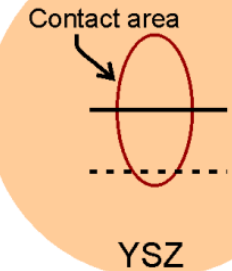

b

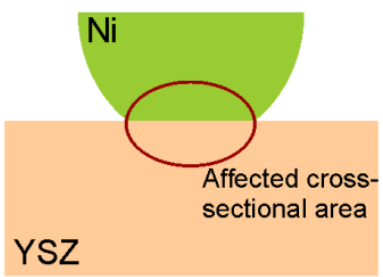

C $\quad \mathrm{Ni}$
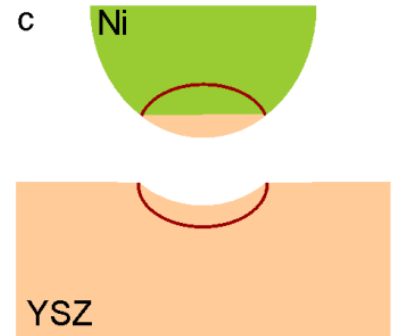

Figure 4. 

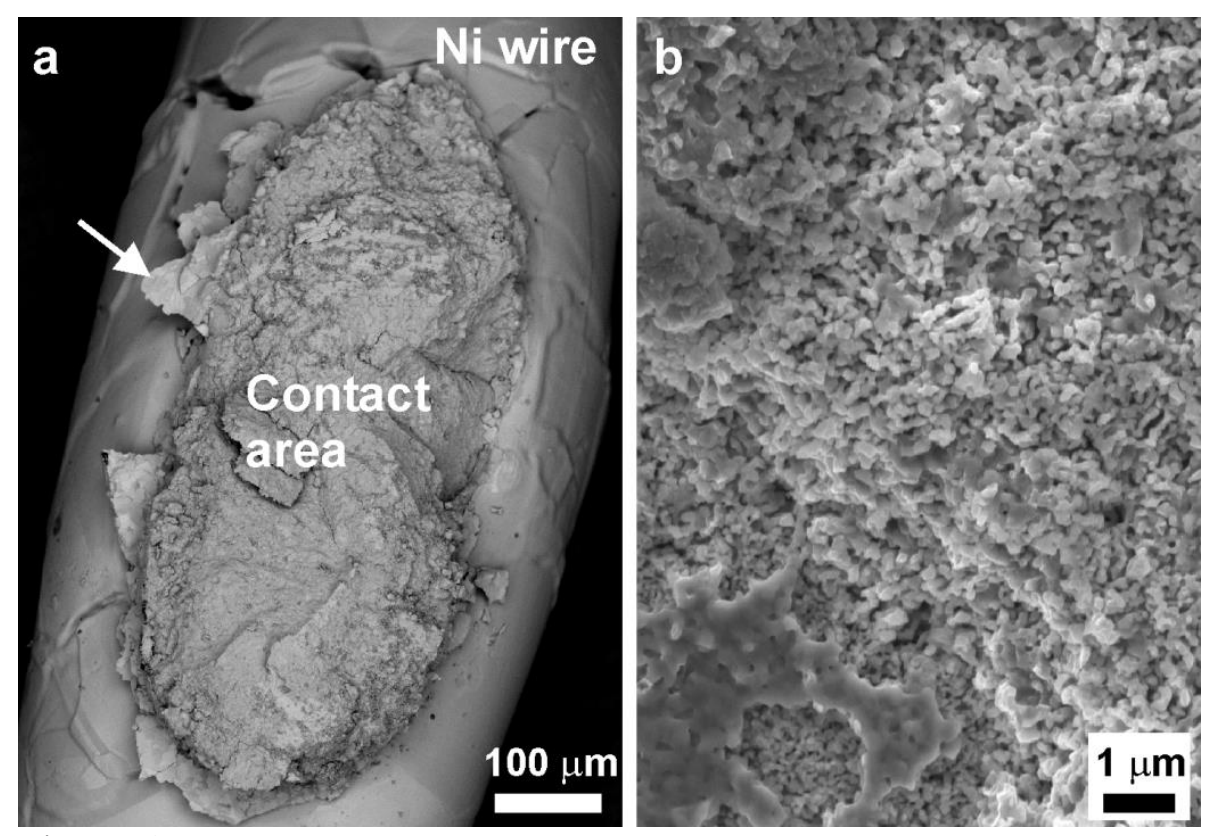

Figure 5.

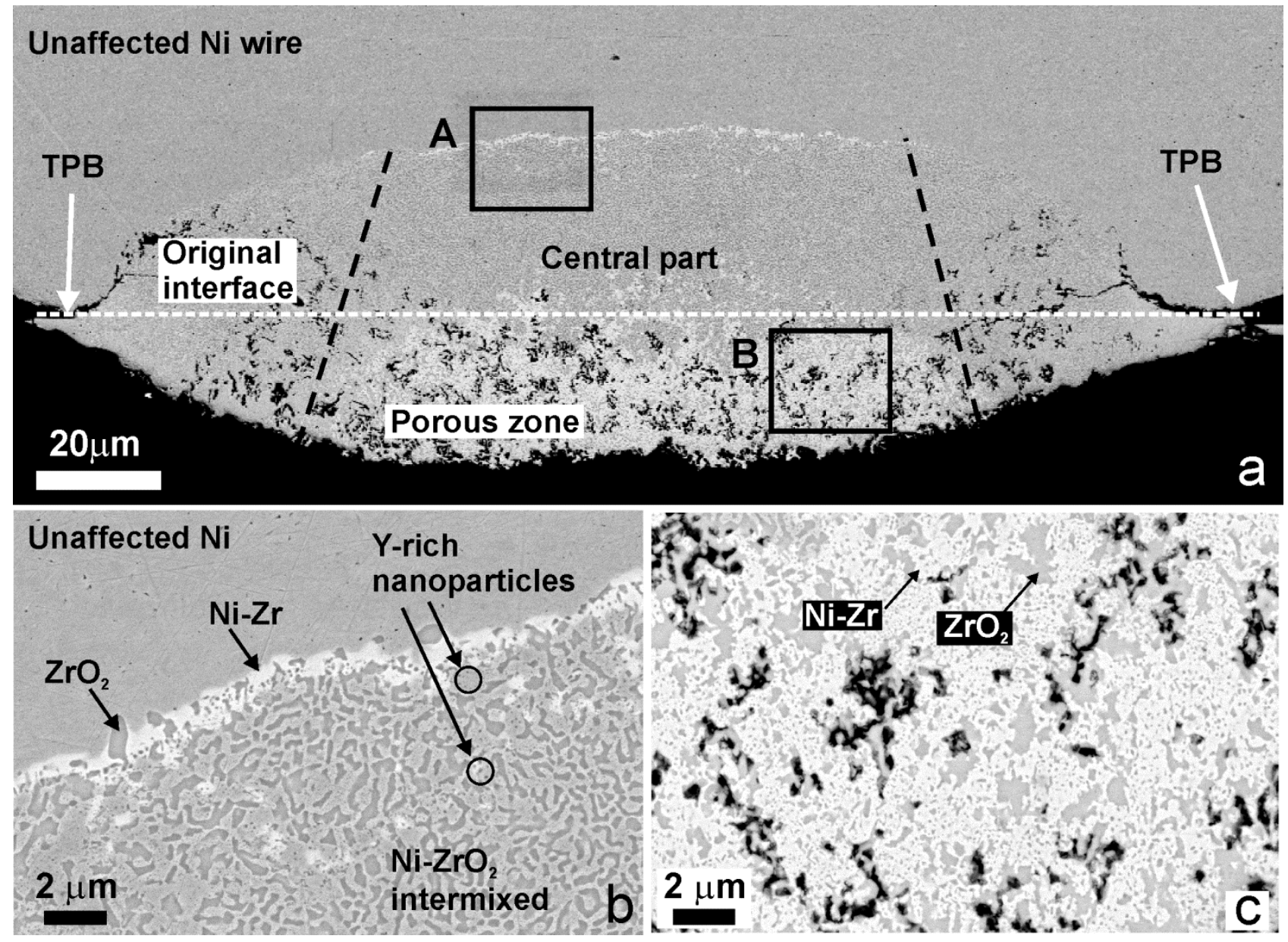

Figure 6. 

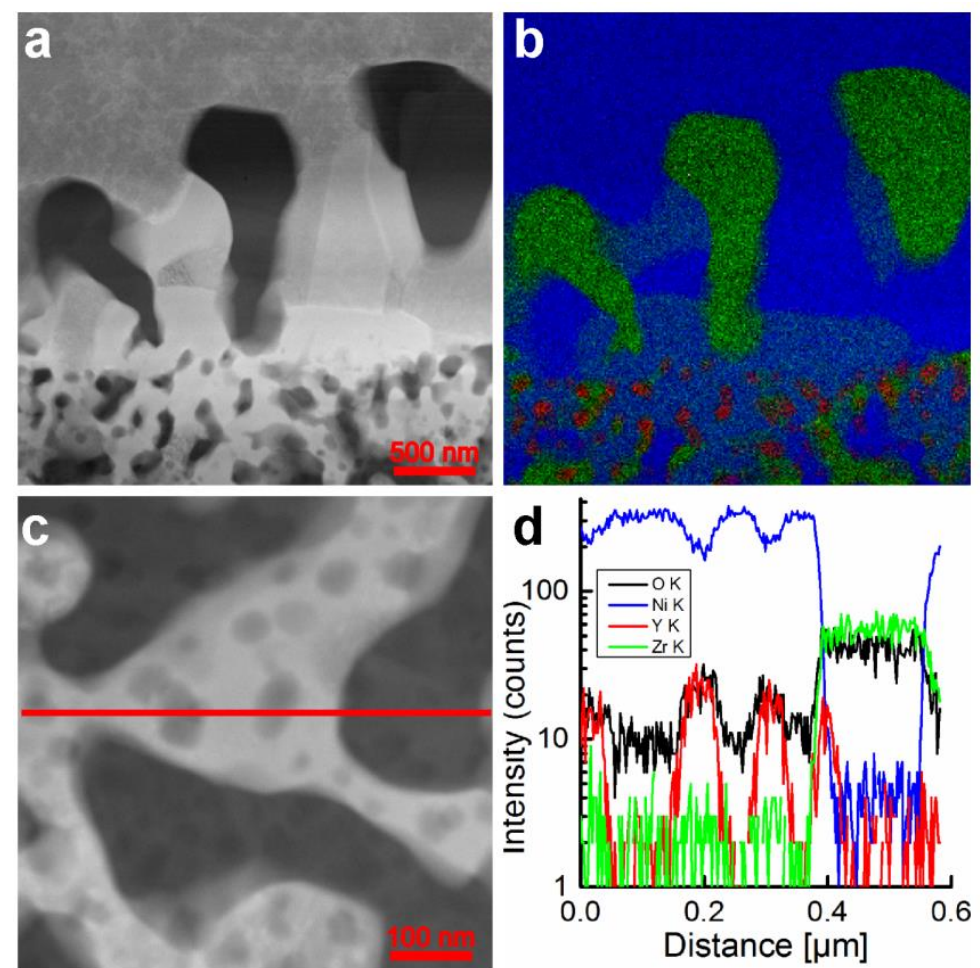

Figure 7. 

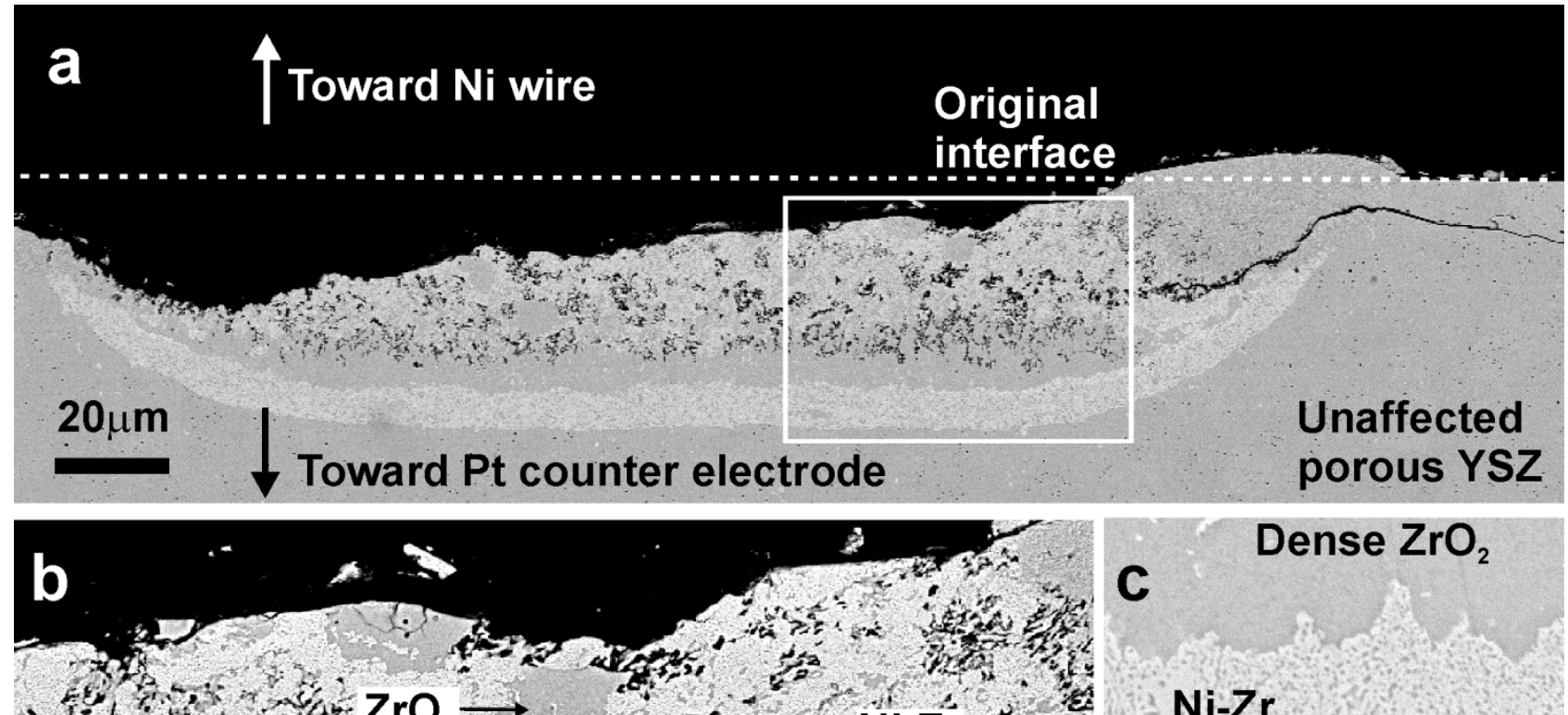

C

Dense $\mathrm{ZrO}_{2}$ 60

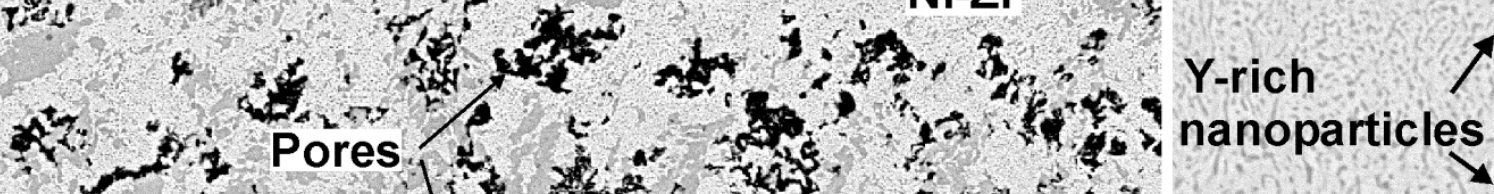

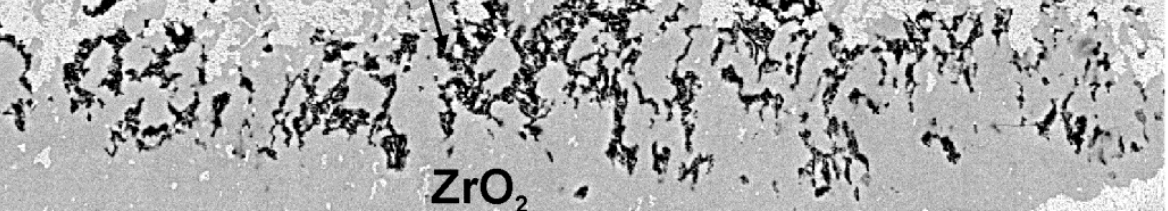

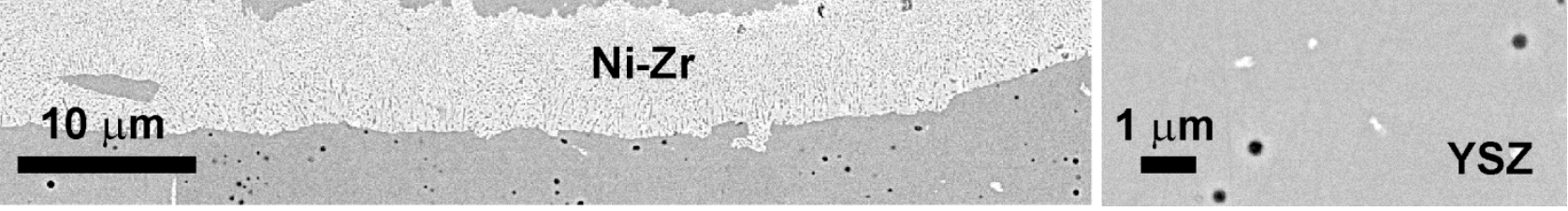

Figure 8 .

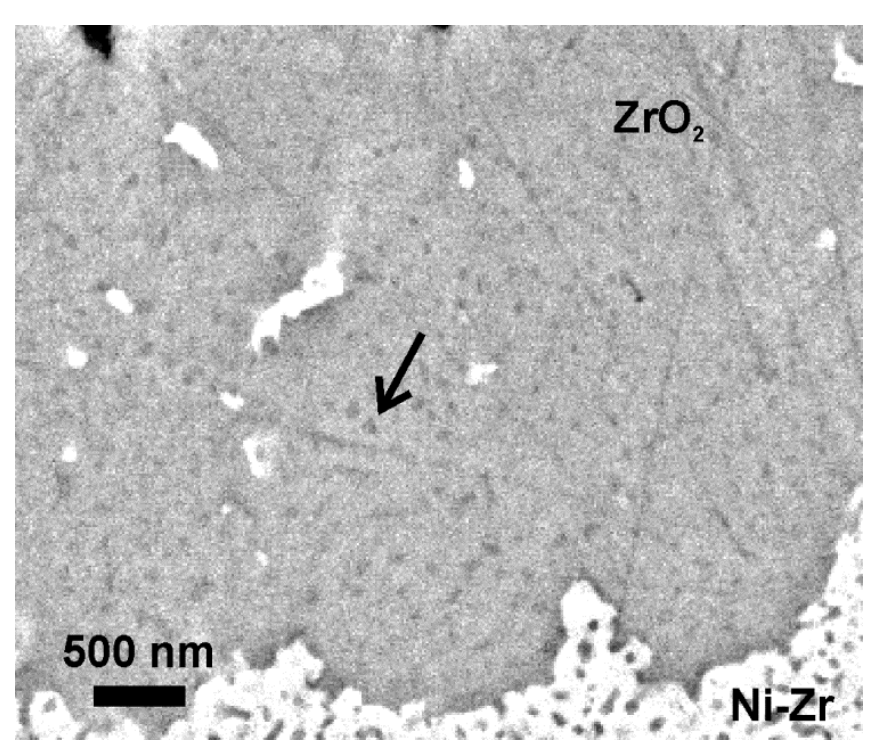

Figure 9. 


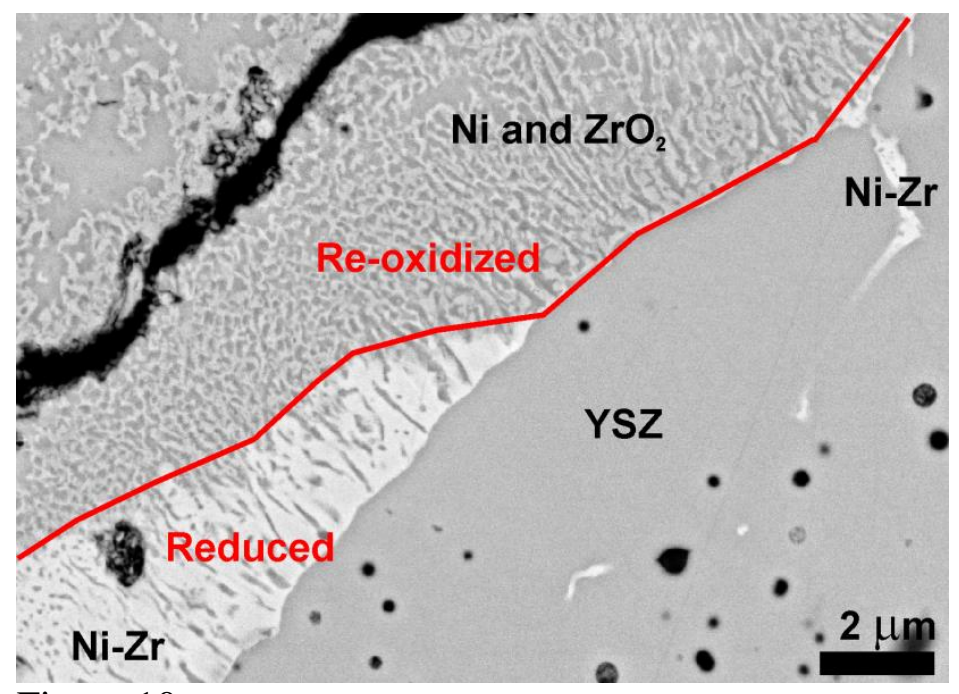

Figure 10.

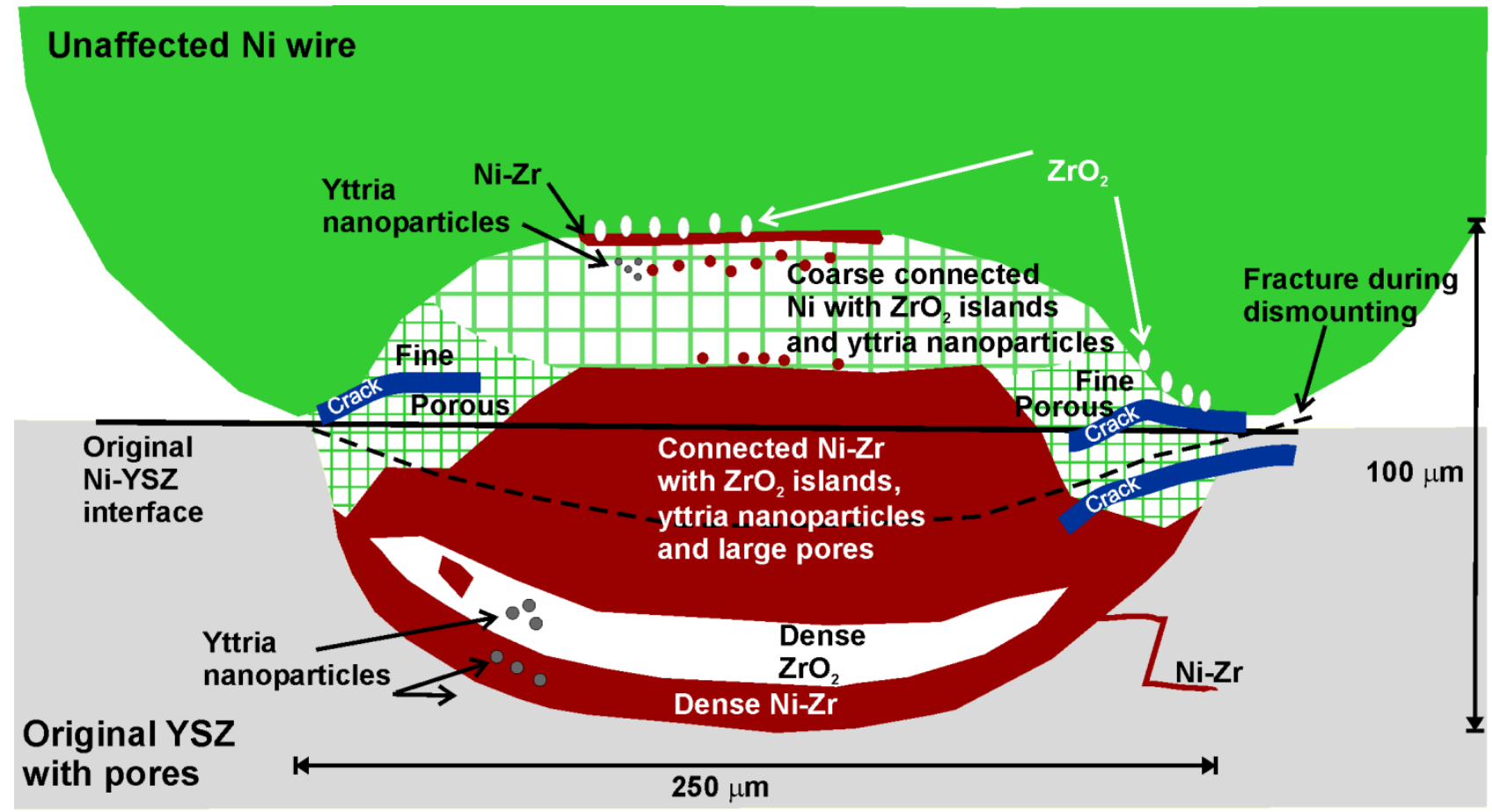

Figure 11. 


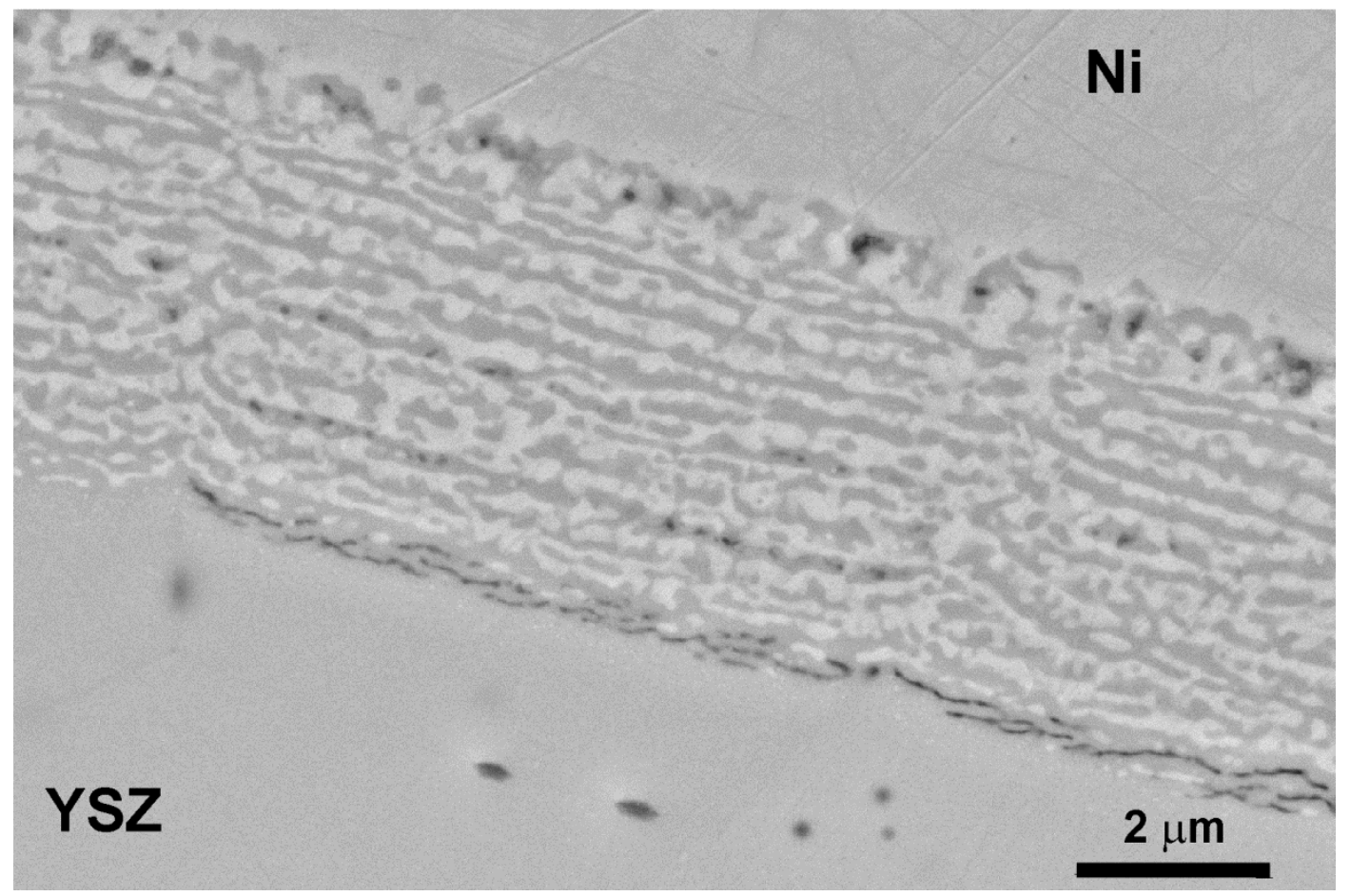

Figure 12.
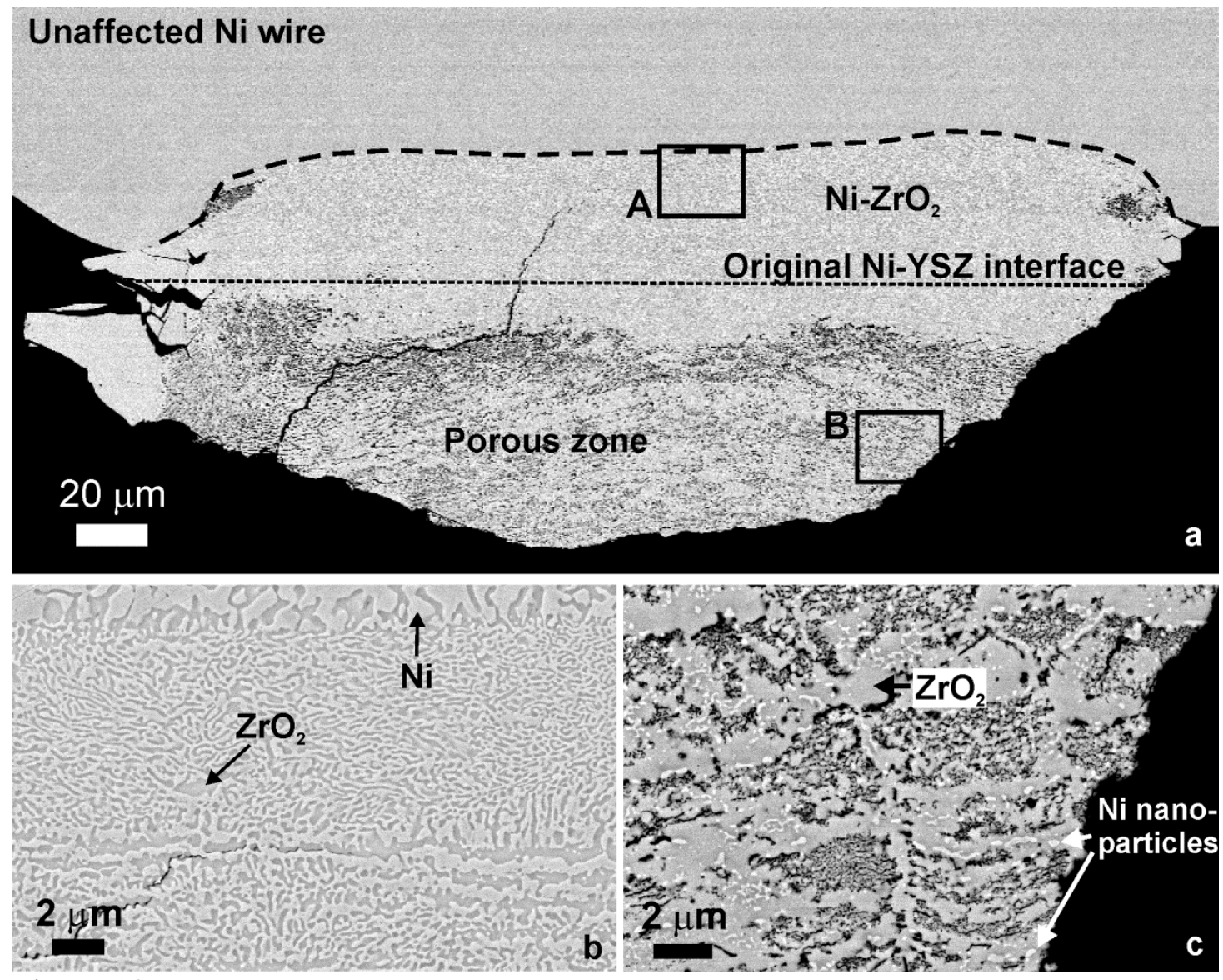

Figure 13. 

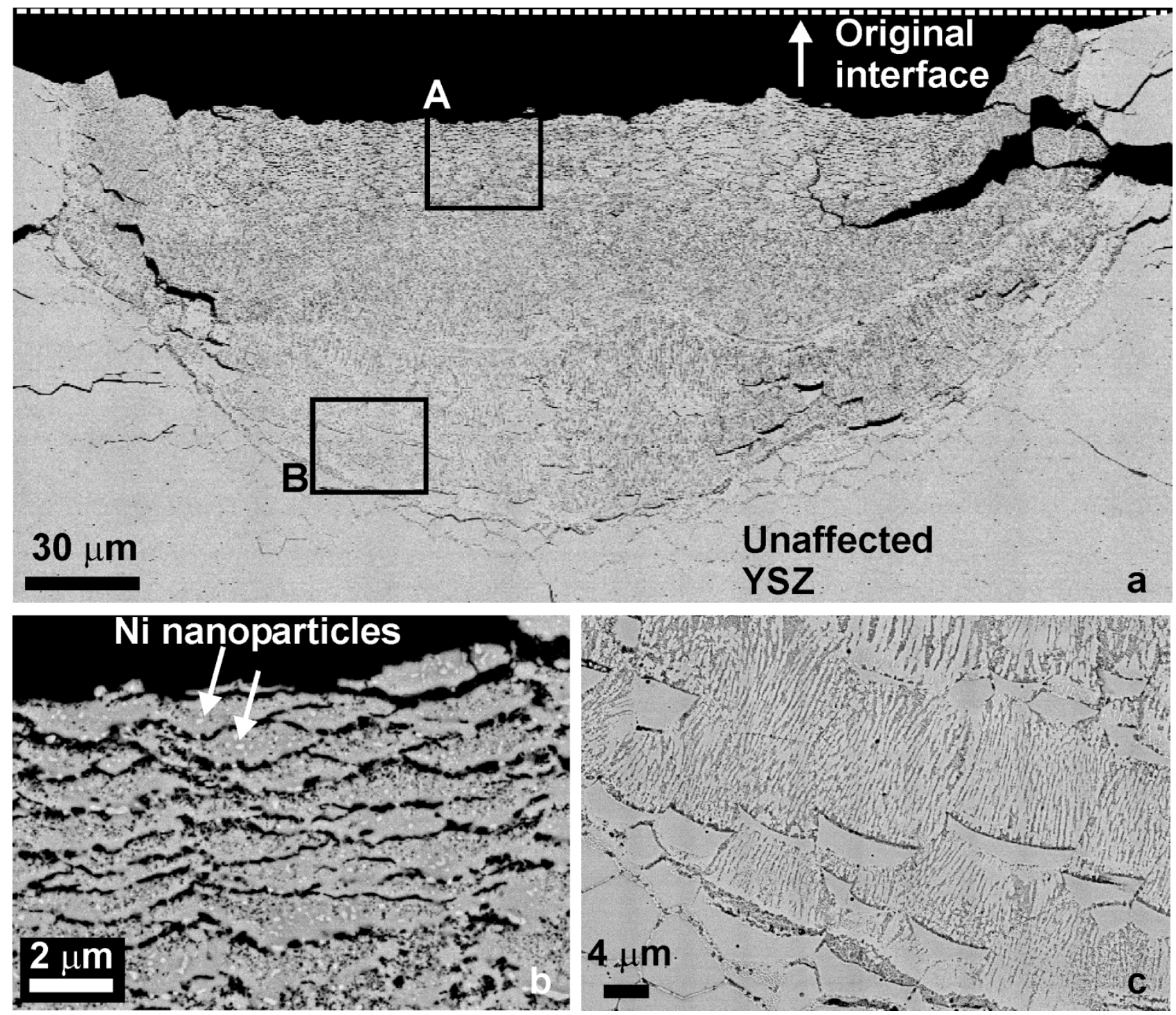

Figure 14. 


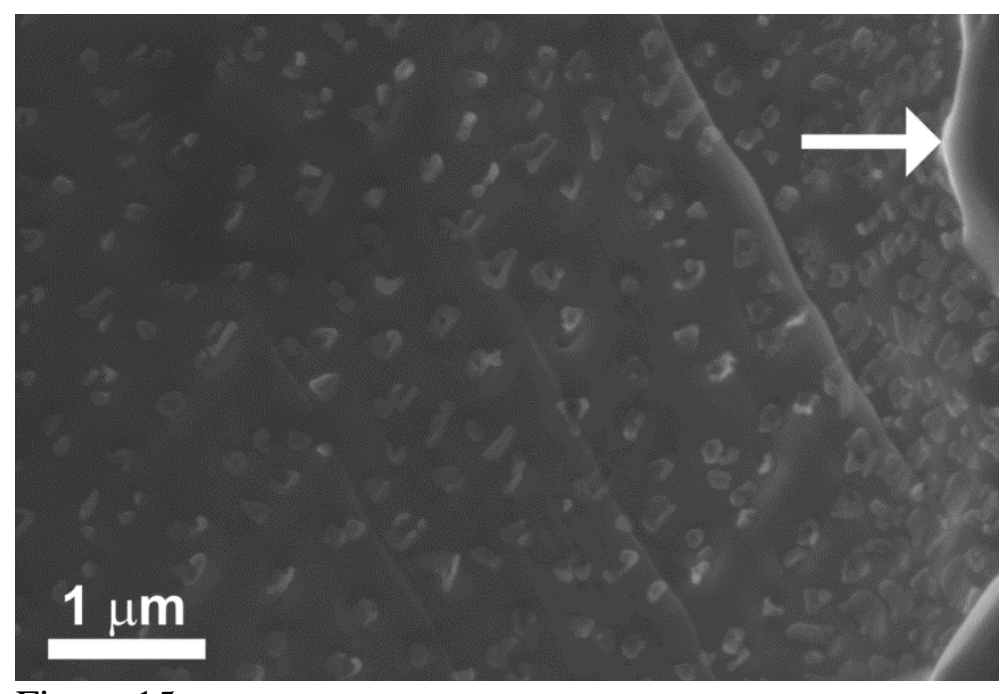

Figure 15.
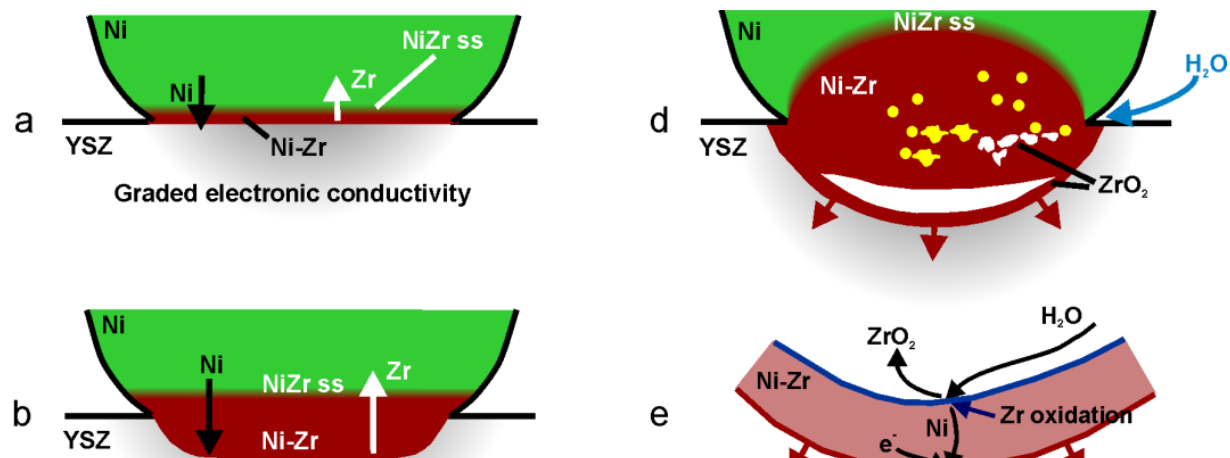

e
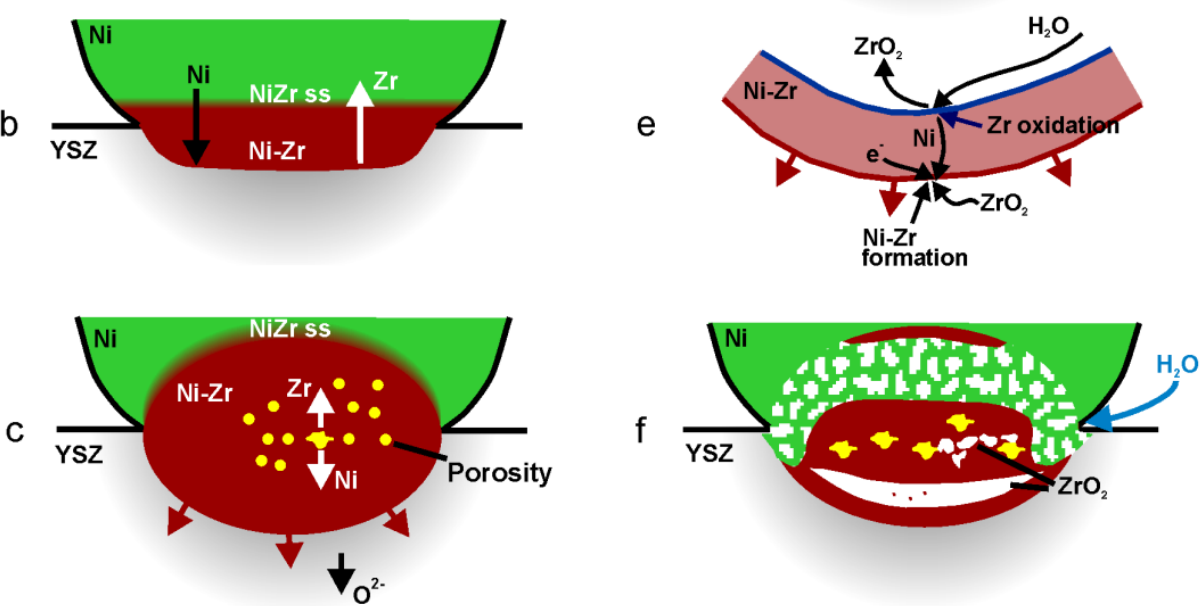

Figure 16. 
Tables

\begin{tabular}{|c|c|c|c|c|c|}
\hline Electrode & $\begin{array}{l}\text { Electrode } \\
\text { potential } \\
(\mathrm{V}) \mathrm{vs} . \\
\mathrm{E}^{\circ}\left(\mathrm{O}_{2}\right)\end{array}$ & $\begin{array}{l}\text { Time at } \\
\text { OCV before } \\
\text { polarization } \\
\text { (h) }\end{array}$ & $\begin{array}{l}\text { Duration of } \\
\text { Polarization } \\
\text { (h) }\end{array}$ & $\begin{array}{l}\text { Time at } \\
\text { OCV after } \\
\text { polarization } \\
\text { (h) }\end{array}$ & $\begin{array}{l}\text { Total time } \\
\text { at } 900{ }^{\circ} \mathrm{C} \\
\text { (h) }\end{array}$ \\
\hline A1 & -2.2 & 710 & 240 & 250 & \multirow{2}{*}{1200} \\
\hline $\mathrm{A} 2$ & -2.0 & 590 & 0.05 & 610 & \\
\hline B0 & -2.3 & 500 & 160 & 55 & \multirow{2}{*}{715} \\
\hline B1 & -2.2 & 150 & 160 & 425 & \\
\hline $\mathrm{C} 0$ & -1.8 & 380 & 450 & 230 & \multirow{3}{*}{1060} \\
\hline C1p & -2.4 & 920 & 140 & - & \\
\hline $\mathrm{C} 2$ & -2.1 & 180 & 160 & 720 & \\
\hline
\end{tabular}

Table 1.

Table caption

Table 2. Electrode potential and duration of polarization for all $\mathrm{Ni}$ electrodes. *For $\mathrm{C} 1 \mathrm{p}$ the polarization was kept during cooling. Due to variations in $R_{s}$ and $i$ during the polarisation, the electrode potentials are estimates with an uncertainty below $100 \mathrm{mV}$. 
Figure and table captions

Figure 1. Sketch of the set-up where a bent Ni wire is pressed against a YSZ surface.

Figure 2. Impedance spectra before and during polarization for electrode B1 (-2.2 V). a) At OCV $1 \mathrm{~h}$ before polarization, b) shortly after polarization, c) after $49 \mathrm{~h}, \mathrm{~d}$ ) after $153 \mathrm{~h}$. Note the difference in scale ( $\mathrm{k} \Omega$ vs. $\Omega$ ). The equivalent circuit shown in Figure $3 \mathrm{c}$ was used to obtain the fits.

Figure 3. Development of a) $R_{s}$ and b) $R_{p}$ with time during polarization. $R_{p}$ is calculated as $1 /\left(1 / R_{l}+1 / R_{2}\right)+R_{3}$. c) Equivalent circuits used for obtaining $R_{s}$ and $R_{p}$. Spectra for the first $90 \mathrm{~h}$ were fitted with the circuit in the blue box whereas later spectra were fitted with the circuit in the red box.

Figure 4. Sketch of the contact area and cross section geometry. a) View from above of an elliptical contact area on YSZ. The full and dashed black lines indicate two positions of cross section, either through the central part or at the end of the long axis. b) During experiments when Ni is pressed against the YSZ and c) after the experiment and dismounting when the Ni electrode and the YSZ disk are separated. The red ellipse marks the area where the microstructure was affected by the polarization. After polarization the Ni electrode is strongly attached to the YSZ disk, and upon dismounting pieces of YSZ are torn out.

Figure 5. a) SEM image (BS) of the contact area on a Ni wire (B1). The arrow points to a piece of YSZ that was torn out from the polished YSZ surface next to the contact area. b) SEM image (inLens) of the nanoporous microstructure in the fracture surface of B0.

Figure 6. SEM (BS) images of a) Ni cross section of C1p, which was polarized during cooling. The original Ni/YSZ interface is established by the polished YSZ and indicated by the dashed line. The central part is characterized by the presence of the intermetallic Ni-Zr phase (brightest phase). b) Magnification of area A showing a rim of $\mathrm{Ni}-\mathrm{Zr}$, the $\mathrm{Ni}-\mathrm{ZrO}_{2}$ intermixed structure and Y-rich nanoparticles. c) Magnification of area $\mathrm{B}$ showing the porous zone containing $\mathrm{Ni}-\mathrm{Zr}, \mathrm{ZrO}_{2}$ and porosities.

Figure 7. a) Dark-field STEM image of the bright rim observed in Figure 6b. b) STEM-EDS elemental map of the same area as (a). K-alpha X-ray signals from Ni (blue), Zr (green) and Y (red) are presented. c) Dark-field STEM image of a region of the intermixed structure below the bright rim observed in Figure 6b). d) STEM-EDS line scan of the line indicated in c).

Figure 8. SEM (BS) images of the cross section of the YSZ part of C1p. The original Ni-YSZ interface is indicated. a) The entire affected area. b) Magnification of the central part, and c) Magnification of the Ni-Zr zone in the bottom of the affected area.

Figure 9. SEM (BS) of nanoparticles present in the dense $\mathrm{ZrO}_{2}$ zone.

Figure 10. SEM (BS) image of the border between the still reduced and re-oxidized zones (Figure 8a). The brightest phase is the intermetallic phase. $\mathrm{Ni}-\mathrm{Zr}$ is found in grain boundaries in the apparently unaffected YSZ several microns below the reduced zone.

Figure 11. Sketch (not to scale) of the entire modified area reconstructed from the cross-sectional image. 
Figure 12. SEM (SE) image of the cross section of the Ni-YSZ interface of electrode A2 after three minutes of polarization at $-2.0 \mathrm{~V}$.

Figure 13. SEM-BS images of the Ni part of the cross section of B1. a) Overview of the entire affected region. b) Magnification of area $\mathrm{A}$ at the border to $\mathrm{Ni}$ showing the intermixed $\mathrm{Ni}$ and $\mathrm{ZrO}_{2}$ microstructure. c) Magnification of area $\mathrm{B}$ in the porous part of the affected region showing numerous $\mathrm{Ni}$ nanoparticles in the $\mathrm{ZrO}_{2}$.

Figure 14. SEM images (BS) YSZ part of the cross section of B1. a) Overview. b) Magnification of area A showing the lenticular features. Ni nanoparticles appear bright. c) Magnification of area B showing the structure with lines of nanopores parallel to the current field. In the lower left corner $\mathrm{Ni}$ and $\mathrm{ZrO}_{2}$ is found between the YSZ grains.

Figure 15. SEM image (InLens) of $\mathrm{ZrO}_{2}$ nanoparticles just outside the contact area (A1). The arrow points to the edge of the contact area.

Figure 16. Stages in the development of the reduction process. a) Formation of interfacial $\mathrm{Ni}-\mathrm{Zr}$ layer. b) Growth of the layer. c) Pore formation. d) Internal oxidation. e) Ni supply across the electrode shell. f) Final oxidation during cooling. 